\title{
Contributing factors common to COVID-19 and gastrointestinal cancer
}

\author{
RONALD NEIL KOSTOFF ${ }^{1}$, MICHAEL BRANDON BRIGGS ${ }^{2}$, DARJA KANDUC ${ }^{3}$, \\ DARLA ROYE SHORES ${ }^{4}$, LEDA KOVATSI ${ }^{5}$, NIKOLAOS DRAKOULIS ${ }^{6}$, \\ ALAN LESLIE PORTER $^{7,8}$, ARISTIDIS TSATSAKIS ${ }^{9}$ and DEMETRIOS A. SPANDIDOS ${ }^{10}$
}

${ }^{1}$ School of Public Policy, Georgia Institute of Technology, Gainesville, VA 20155; ${ }^{2}$ Independent Consultant, Roscommon, MI 48653, USA; ${ }^{3}$ Department of Biosciences, Biotechnologies and Biopharmaceutics, University of Bari, I-70125 Bari,

Italy; ${ }^{4}$ Department of Pediatrics, Division of Gastroenterology, Johns Hopkins University School of Medicine, Baltimore, MD 21287, USA; ${ }^{5}$ Laboratory of Forensic Medicine and Toxicology, School of Medicine, Aristotle University of Thessaloniki, 54124 Thessaloniki; ${ }^{6}$ Research Group of Clinical Pharmacology and Pharmacogenomics, Faculty of Pharmacy, School of Health Sciences, National and Kapodistrian University of Athens, 15771 Athens, Greece; ${ }^{7}$ R\&D, Search Technology, Inc., Peachtree Corners, GA 30092; ${ }^{8}$ School of Public Policy, Georgia Institute of Technology, Atlanta, GA 30332, USA; ${ }^{9}$ Department of Forensic Sciences and Toxicology, Faculty of Medicine, and ${ }^{10}$ Laboratory of Clinical Virology, Medical School, University of Crete, 71003 Heraklion, Greece

Received September 12, 2021; Accepted November 4, 2021

DOI: $10.3892 /$ or.2021.8227

\begin{abstract}
The devastating complications of coronavirus disease 2019 (COVID-19) result from the dysfunctional immune response of an individual following the initial severe acute respiratory syndrome coronavirus 2 (SARS-CoV-2) infection. Multiple toxic stressors and behaviors contribute to underlying immune system dysfunction. SARS-CoV-2 exploits the dysfunctional immune system to trigger a chain of events, ultimately leading to COVID-19. The authors have previously identified a number of contributing factors (CFs) common to myriad chronic diseases. Based on these observations, it was hypothesized that there may be a significant overlap between $\mathrm{CFs}$ associated with COVID-19 and gastrointestinal cancer (GIC). Thus, in the present study, a streamlined dot-product approach was used initially to identify potential CFs that affect COVID-19 and GIC directly (i.e., the simultaneous occurrence of CFs and disease in the same article). The nascent character of the COVID-19 core literature ( 1-year-old) did not allow sufficient time for the direct effects of numerous CFs on COVID-19 to emerge from laboratory experiments and epidemiological studies. Therefore, a literature-related discovery approach was
\end{abstract}

Correspondence to: Dr Ronald Neil Kostoff, School of Public Policy, Georgia Institute of Technology, 13500 Tallyrand Way, Gainesville, VA 20155, USA

E-mail: rkostoff@gmail.com

Key words: coronavirus disease 2019, severe acute respiratory syndrome coronavirus 2, gastrointestinal cancer, colon cancer, stomach cancer, esophageal cancer, immune system dysfunction, contributing factors, literature-related discovery used to augment the COVID-19 core literature-based 'direct impact' CFs with discovery-based 'indirect impact' CFs [CFs were identified in the non-COVID-19 biomedical literature that had the same biomarker impact pattern (e.g., hyperinflammation, hypercoagulation, hypoxia, etc.) as was shown in the COVID-19 literature]. Approximately 2,250 candidate direct impact CFs in common between GIC and COVID-19 were identified, albeit some being variants of the same concept. As commonality proof of concept, 75 potential CFs that appeared promising were selected, and 63 overlapping COVID-19/GIC potential/candidate $\mathrm{CFs}$ were validated with biological plausibility. In total, 42 of the 63 were overlapping direct impact COVID-19/GIC CFs, and the remaining 21 were candidate GIC CFs that overlapped with indirect impact COVID-19 CFs. On the whole, the present study demonstrates that COVID-19 and GIC share a number of common risk/CFs, including behaviors and toxic exposures, that impair immune function. A key component of immune system health is the removal of those factors that contribute to immune system dysfunction in the first place. This requires a paradigm shift from traditional Western medicine, which often focuses on treatment, rather than prevention.

\section{Introduction}

Overview. The present study aimed to demonstrate commonality between the contributing factors ( $\mathrm{CFs}$ ) to coronavirus disease 2019 (COVID-19) and gastrointestinal cancer (GIC), and to demonstrate that the bases for these superficially different diseases have important similarities. Much of the underlying motivation for the present study has been previously presented $(1,2)$ and is thus not repeated herein.

The virus associated most closely with COVID-19 [severe acute respiratory syndrome (SARS)-coronavirus 2 (CoV-2)] 
is transmissible. The occurrence of serious consequences from this transmission is dependent on the health of the host's immune system (3-5). In the model proposed by the authors, these severe consequences of COVID-19 result from the effective exploitation of a dysfunctional immune system by the SARS-CoV-2 virus. In this exploitive process, genetic disposition and real-life exposures to multiple toxic stressors, as well as toxic behaviors, lay the groundwork for immune system dysfunction. Following SARS-CoV-2 exposure, the dysfunctional immune system is unable to neutralize the SARS-CoV-2 virus, thereby allowing the virus to enter and replicate in cells and trigger a chain of events, ultimately leading to COVID-19 $(3,4)$.

If immune system dysfunction is a/the major factor in the severity of both infectious and chronic diseases, then a necessary, although not necessarily sufficient, condition for prevention and successful longstanding treatment is a reduction of those factors that contribute to immune system dysfunction. The virology-centric approach currently used for COVID-19 reflects damage control for a dysfunctional immune system (e.g., quarantine, face masks, vaccines, anti-viral treatments, etc.). A toxicology-centric approach would be aimed at identifying and removing the CFs to immune system dysfunctionality. Its evidentiary basis would require going beyond current single-stressor laboratory experiments to more comprehensive stressor combination experiments $(2,6)$.

It was hypothesized that the links between CFs to COVID-19 and GIC are similar, based on independent observations of chronic disease CFs and COVID-19 CFs. The present study aimed to examine this hypothesis.

Notable demonstrations of the present study. Myriad techniques were developed/exploited and integrated for the present study, and are explained in detail in the Data and methods section. Multiple findings resulted from this approach, although two major demonstrations stand out.

First was the demonstration that a number of crucial $\mathrm{CFs}$ common to GIC and COVID-19 exist. This provides evidence of the unity of diseases (infectious and chronic) heretofore considered and treated as separate entities, and is a step along the pathway to a unified theory of disease.

Second was the demonstration that CFs indirectly related to COVID-19 (the CF did not appear in the COVID-19 core literature, but was located in a literature directly related to COVID-19; e.g., hyperinflammation, hypercoagulation, hypoxia, etc.) exhibited high promise of being validated eventually as directly related to COVID-19 (the CF appeared in in the COVID-19 core literature). Having the ability to identify promising CFs using literature related directly to the target disease literature is the mirror image of having the ability to identify promising treatments for repurposing, and would be of substantial value to researchers, research managers, research sponsors, and venture capitalists. It would also serve as an early warning indicator and allow precautionary preventive steps to be taken for a target disease of interest before a $\mathrm{CF}$ had been confirmed as directly related to that disease.

\section{Commonality of CFs to GIC and COVID-19}

Background. The first author and colleagues have been developing protocols to prevent and reverse chronic diseases $(7,8)$.
The central component of these unique protocols is the identification and elimination of CFs to these chronic diseases. However, the question arises of whether the aforementioned approach for preventing and reversing chronic diseases can be applied successfully for preventing and reversing communicable diseases that exploit immune system dysfunction, such as COVID-19.

COVID-19. Over the past two decades, there have been at least three major coronavirus-based infectious disease outbreaks/epidemics/pandemics: SARS in 2002-2003; Middle East respiratory syndrome (MERS), which commenced in 2012; and COVID-19, which commenced in December, 2019. A comparative analysis of the clinical and laboratory differences and similarities among SARS-CoV, MERS-CoV and SARS-CoV-2 (presented in Table I) highlights two points: i) The most common clinical symptoms (such as fever, cough, myalgia, etc.) that were present have relatively similar extent in patients with MERS and SARS-CoV-2; ii) in synchrony, laboratory findings documented similar alterations of metabolic markers.

The literature data appear to underline various immunological characteristics among SARS-CoV, MERS-CoV and SARS-CoV-2 (9). Given the caveat that the cytokine profile is extremely variable by depending on numerous factors such as the phase of clinical course, disease severity, and types of cytokines analyzed; inter alia, it is of particular interest to mention that the cytokine profile has been found to be practically unaltered in patients with MERS-CoV who developed severe disease (10). Indeed, as previously demonstrated, interferon (IFN)- $\gamma$, interleukin (IL)-10, IL-12p70, IL-12/IL-23p40 and IL-17 were not detected in the serum of any patients with MERS-CoV during the course of disease. Only IFN- $\beta$, tumor necrosis factor (TNF)- $\alpha$, transforming growth factor (TGF)- $\beta 3$ and IL-1 $\alpha$ were detected in a few patients, although they did not exhibit any significant association with the clinical course or the severity of illness (10). Hence, these data may suggest a dominant role of the disrupted cytokine profile, i.e., the so-called cytokine storm, in determining the disease severity that affects the SARS patients (11). Finally, another crucial similarity among them is the demographic affected most severely: The elderly population and others who have comorbidities associated with dysfunctional immune systems $(1,3,12-16)$.

GIC. Nature Research (17) defines the scope of GIC as: 'malignant conditions of the gastrointestinal (GI) tract and other organs involved in digestion, including the esophagus, stomach, biliary system, pancreas, small intestine, large intestine, rectum and anus'. To generate the core GIC literature required for the present study, the MeSH Tree scope (which includes Pubmed MeSH terms only) (18) was selected, and this was augmented with the text equivalents of the myriad cancers listed on the MeSH Tree for GIC. The final GIC query selected for GIC core literature retrieval from Pubmed is presented as supplementary material (Appendix S1).

As regards, incidence and prevalence, GIC is a relatively prevalent cancer. Worldwide, the GIC burden remains high (19). In the USA, colorectal cancer was the fourth leading cause of new cancer diagnoses in 2020 (20). Globally, colorectal cancer also has the fourth highest incidence, with 1.9 million annual diagnoses (19). Stomach cancer was the 
Table I. Comparative clinical and laboratory overview of MERS and SARS ${ }^{\text {. }}$

\begin{tabular}{|c|c|c|c|}
\hline Parameter & SARS-CoV (\% of patients) & MERS-CoV (\% of patients) & SARS-CoV-2 (\% of patients) \\
\hline \multicolumn{4}{|l|}{ Clinical characteristics } \\
\hline Fever & $99-100$ & $40-98$ & $65-99$ \\
\hline Cough & $29-100$ & $18-87$ & $22-82$ \\
\hline Myalgia & $20-60$ & $7-32$ & $11-44$ \\
\hline Shortness of breath & $20-60$ & $27-72$ & $4-35$ \\
\hline Dyspnea & $42-44$ & $5-15$ & $17-40$ \\
\hline Chills & $15-74$ & $7-87$ & $7-17$ \\
\hline Diarrhea & $10-50$ & $7-44$ & $1-10$ \\
\hline Vomiting or nausea & $10-35$ & $7-21$ & $1-13$ \\
\hline Chest pain & 30 & 15 & 2 \\
\hline Headache & $15-70$ & $5-13$ & $4-8$ \\
\hline Sore throat & $11-30$ & $4-1$ & $4-26$ \\
\hline \multicolumn{4}{|l|}{ Laboratory findings } \\
\hline Leukopenia $<4 \times 10^{9}$ & $7-34$ & $6-14$ & $17-25$ \\
\hline Lymphopenia $<1 \times 10^{9}$ & $54-75$ & 35 & $35-70$ \\
\hline Thrombocytopenia & $20-44.8$ & $17-36$ & 21 \\
\hline Lactate dehydrogenase $\uparrow$ & $71-87$ & $47-49$ & $40-98$ \\
\hline Alanine transaminase $\uparrow$ & $23-56$ & 11 & $17-31$ \\
\hline Aspartate transaminase $\uparrow$ & $32-78$ & $15-53$ & $30-37$ \\
\hline Mortality rate & $3.6-30$ & $60-65$ & $4-28$ \\
\hline
\end{tabular}

${ }^{a}$ The information shown in the table has been adapted from a previous study (9). SARS-CoV, severe acute respiratory syndrome coronavirus; MERS Middle East respiratory syndrome. The upward arrows ( $\uparrow$ denote an increase.

5th most common diagnosis, with 1.1 million cases (19). The incidence of esophageal cancer was 604,000 (19).

The risk factors for the development of GIC may be affected by genetic predisposition, geographic location, infection, toxic exposures and other medical conditions or treatments (21-24); however, several risk factors are modifiable, including diet, physical activity, alcohol consumption and smoking $(25,26)$. As obesity has become increasingly prevalent worldwide, increasing associations between obesity and the risk of GICs have been identified (27). There are likely several mechanisms involved, including alterations in endocrine signaling, a relatively high fat and processed meat consumption coupled with a low fiber intake that influences intestinal microbes and immune response, and altered inflammatory cytokines from adipose tissue $(27,28)$.

Toxicology. In its broadest sense, toxicology is the study of the impact that toxic stimuli and toxic behaviors, as well as their combinations, can have on all members of the animal kingdom and their environment. Its two most important components are epidemiological-type studies to identify potential adverse effects of candidate toxic stimuli and behaviors, and laboratory studies to identify mechanisms that link the stimuli to their adverse effects. Toxic stimuli exposures or toxic behaviors can range from acute to chronic, and the doses can span a wide spectrum.

It is well documented that exposure to a wide variety of stimuli, whether they are anthropogenic chemicals (e.g., xenobiotics) or lifestyle-related, etc., is associated with an increased prevalence of chronic diseases. In some cases, the underlying mechanism includes the dysfunction of the immune system. Exposure to particulate matters, fossil fuel derivatives, metals, ultraviolet (UV)-B or ionizing radiation, etc., may contribute to immunodeficiency, which in turn may contribute to the development of chronic diseases. This could critically elevate viral epidemic or even pandemic events and prevalence, such as in the COVID-19 pandemic $(3,29)$, or metabolic disorders (27). A further underlying mechanism may involve metabolic disorders. Chronic inflammation may be promoted by the exposure to stressors during a life course, such as environmental toxicants, processed food (30), infectious agents, overfeeding, or drugs. The improvement of the immune response and inflammatory markers may lead to an improved physiological resilience to disturbances by infectious agents, such as viruses and bacteria, and may possibly lead to milder COVID-19 symptoms.

The robustness of the immune system appears to play a pivotal role. It has even been suggested that it may affect vaccine safety and efficiency (4). Human host autoimmune pathologies may be triggered due to sequence similarities between peptides, introduced by vaccines and human proteins. The protective anti-SARS-CoV-2 antibody immune response may result in a pathogenic autoimmune attack against a genetically predisposed human vaccine recipient. Possible stimuli implicated in the aforementioned mechanism include alcohol consumption, as well as exposure to various toxic metals $(31,32)$.

The functional improvement of the immune system to maintain metabolic homeostasis may be achieved by 
administrating specific dietary components, such as fibers and polyphenols, as well as lifestyle changes (e.g., physical exercise), thus maintaining metabolic homeostasis and preventing disease development (33).

Similarly, serum zinc, copper and the metabolism of other biometals, as well as serum metal levels and metal balance and homeostasis, appear to play a crucial role in the mechanisms that affect disease severity by interfering with COVID-19 pathogenesis; these may thus be exploited as COVID-19 severity markers (34).

Relevance to chronic and infectious diseases. In previous studies, authors have demonstrated that the onset and exacerbation of chronic (7) and infectious diseases (3) are greatly affected by toxic modifiable CFs (with genetic factors having different levels of influence). The present study demonstrates that there is strong overlap between the CFs for GIC and COVID-19. Thus, while the outward manifestations (symptoms) of the two diseases appear to differ, some fundamental causes are similar. This may be the reason that the majority of severe consequences of COVID-19 occur in those patients with high comorbidities; the comorbidities and COVID-19 are two sides of the same coin.

Toxicological components constitute the bulk of modifiable CFs responsible for GIC and COVID-19. In both cases, the effects of these toxicological components on the immune system and circulatory system appear to be major contributors to the symptoms and outcomes observed, primarily through increases in inflammation and oxidative stress. Examples of immune system dysfunction center around the hyperinflammation/cytokine storm and severe allergic reactions, while circulatory system dysfunction centers around changes in i) serum properties, such as hypercoagulation; and ii) cardiovascular markers, such as elevated troponin and D-dimer levels. In GIC, the interactions between the immune system and the microbiome (35-38) (Fig. 1) become critical due to the cancer localization in the digestive tract.

Inflammatory factors and coagulation changes exhibit similar clinical manifestations in COVID-19 and GIC. In hospitalized patients with COVID-19, serum IL-6, IL-8, IL-1 $\beta$ and TNF- $\alpha$ levels are an inflammatory cytokine signature linked to coagulopathy and are predictive of COVID-19 severity and associated survival $(39,40)$. Mechanistically, alterations in this inflammatory cytokine signature and the resulting inflammation and tissue injury can function as inducers of increased signaling by thrombin (proteinase-activated) and purinergic receptors, which promote platelet activation and hypercoagulation events, thus determining hypercoagulability (41). In particular, it should be emphasized that increased levels of TNF- $\alpha$ represent a risk determinant for venous thromboembolism (42).

Such a scheme of altered inflammatory factors leading to coagulation disorders appears to be reflected in GIC. In fact, alterations in the levels of IL-8, IL-10 and TNF- $\alpha$ may play crucial roles in the development of gastric cancer (43); TNF- $\alpha$ /TNFR1 signaling promotes gastric tumorigenesis (44); TNF- $\alpha$ gene promoter polymorphisms are linked to a risk of developing venous thromboembolism (45). In essence, alterations in a selected cytokine profile and, in particular, in the levels of TNF- $\alpha$ appear to be a main factor of hyperinflammation and hypercoagulopathy in both COVID-19 and GIC.
The toxicological components included in the present study cover toxic lifestyles (diet, activity, sleep, substance abuse, etc.), medical procedures (drugs, diagnostics, surgery, non-drug therapies, etc.), bio-organisms (fungi, mold, parasites, viruses, bacteria, etc.), environments, occupations, psychosocial events and socioeconomic environments. The laboratory-based evidence for the toxicity of the majority of toxic substances is obtained through single-stressor laboratory experiments, which under-represent real-world effects. The combinations of toxic stimuli reflect real-world exposures, and the doses of substances that can cause damage in combinations are lower than those that can cause damage in single-stressor experiments of those substances. Each of these factors plays a key role in such chronic exposure paradigms, revealing the importance of required further toxic evaluations in order to discover possible routes that would eventually lead to a human risk.

The rapidly growing body of scientific evidence on COVID-19 indicates that in order for a patient to exhibit serious symptoms and side-effects, an underlying dysfunction of the immune system is necessary. Various factors, including genetic predisposition and exposure to toxic stimuli, aid the virus in rendering the immune system vulnerable.

Literature-related discovery and innovation (LRDI). LRDI has been previously described in detail (46-48), and only the essential features relevant to the present study (the discovery component of LRDI: LRD) will be summarized herein. LRD and its subset literature-based discovery (LBD) link two or more disparate literatures to produce discovery. In the medical world, the main application of LRD has been to identify novel treatments for disease $(48,49)$, also known as treatment repurposing. The LRD process uses pattern matching to link the disparate literatures.

For example, a disease of interest may have hyperinflammation, hypercoagulation and hypoxia as its main characteristics. In that case, the non-disease of interest literature would be searched for records that contain various combinations of hyperinflammation, hypercoagulation and hypoxia. If the purpose of the search is to identify novel treatments for the disease of interest, then substances/behaviors (in the retrieved records) that reduce hyperinflammation, hypercoagulation and hypoxia would be viewed as candidate treatments for the disease of interest. If the purpose of the search is to identify novel CFs for the disease of interest, then substances/behaviors (in the retrieved records) that increase hyperinflammation, hypercoagulation and hypoxia would be viewed as candidate CFs for the disease of interest.

The characteristics mentioned above can be specified at a number of different hierarchical levels of detail. Consider inflammatory bowel disease (IBD), which encompasses chronic inflammatory GI disorders categorized most commonly as Crohn's disease (CD) and ulcerative colitis (UC). IBD is described in more detail in prior studies $(2,48)$. A previous IBD treatment repurposing study by the first author and colleagues mainly used specific biomarkers and their desired directions of value change (e.g., reduce IL- $\beta$ AND/OR reduce IL-6 AND/OR reduce C reactive protein, etc.) as the pattern to identify records that may contain novel IBD treatments (48).

In a recent IBD-COVID-19 CF commonality study (2), the authors used a much more general biomarker specification 


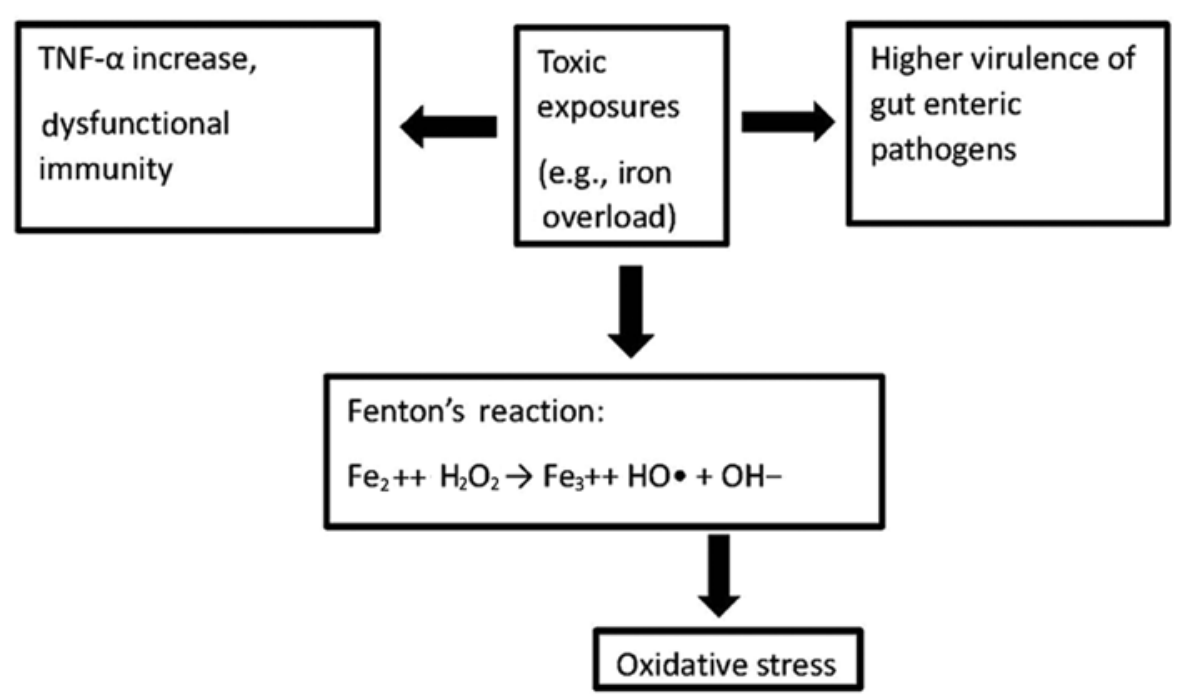

Figure 1. Iron overload alters the immune system by promoting TNF- $\alpha$ secretion $(35,36)$, induces oxidative stress by generating the powerful hydroxyl radical (37), and promotes the replication and virulence of gut pathogen microbiome (38).

as the pattern to identify records that may contain novel COVID-19 CFs not identified previously in the COVID-19 core literature. The encompassing characteristic of the COVID-19 core literature was viewed as immune system dysfunction. This broad characteristic was used as the pattern for searching the non-COVID-19 biomedical literature for records that contained biomarkers and symptoms of immune system dysfunction and associated substances/behaviors. Specifically, the non-COVID-19 immune system dysfunction literature was searched for candidate CFs identified from the dot-product approach (intersection of lists of known toxic stimuli with phrases in the literature of interest) applied to the IBD core literature. If the retrieved records contained biomarkers and symptoms reflective of immune system dysfunction, these candidate CFs became validated CFs for COVID-19. As demonstrated in Appendix S1, the LRD approach used for the present study contains terms both at the specific biomarker level and at the much more encompassing general biomarker level.

Identification of CFs common to GIC and COVID-19. The present study used three separate literatures to identify CFs common to GIC and COVID-19 (see Appendix S1 for the queries used to retrieve these three literatures). First was a mature GIC core literature spanning 1990-early 2021, and it was used to identify CFs that had a direct impact on GIC (i.e., the $\mathrm{CF}$ was contained in a GIC core literature record(s). Second was a predominately nascent COVID-19 literature (whose main component was focused strictly on COVID-19 and was primarily $\leq 9$ months old, and whose very minor component included other coronaviruses), and it was used to identify CFs that had a direct impact on COVID-19. Third was a mature literature linked to, but not contained within, the COVID-19 core literature. This linked literature was used to identify CFs that had an indirect impact on COVID-19, and was called the discovery literature. These latter CFs affected the entities that linked this related literature to the COVID-19 core literature. For example, if a key characteristic of the COVID-19 core literature is immune system dysfunction, and immune system dysfunction is a link to this third literature, then a $\mathrm{CF}$ to immune system dysfunction identified in the third literature, but not contained in the COVID-19 core literature, has the potential to impact COVID-19 indirectly through the immune system dysfunction link from the non-COVID-19 literature to the COVID-19 literature.

Commonality was determined between i) CFs that impacted GIC directly; and ii) CFs that impacted COVID-19 directly and indirectly using a streamlined dot-product approach to identify the CFs that impacted COVID-19 and GIC directly, and a literature-related discovery approach to identify the CFs that impacted COVID-19 indirectly. Modifiable CFs that contribute to both GIC and COVID-19 were identified.

The COVID-19 core literature was viewed as insufficient for the identification of the COVID-19 CFs due to its nascency and immediacy. The main emphases of the COVID-19 core literature titles are the following: i) Containing the pandemic; ii) identifying the major abnormal biomarker values and symptoms of patients hospitalized with COVID-19; iii) repurposing and testing treatments; iv) developing and testing vaccines; v) assessing the effects of the pandemic on behaviors, medical treatments and procedures; and vi) reviews of treatments, vaccines, restrictions, etc. In brief, the COVID-19 core literature as of early March, 2021, was mainly focused on disease/viral containment rather than prevention.

As of March, 2021, there has been insufficient time to conduct the lengthy laboratory experiments relating CFs to COVID-19 or to conduct the longer-term epidemiological studies required to reveal these associations. Therefore, a more mature intermediate literature that shares commonalities with important aspects of the COVID-19 core literature, and includes the longer-term studies that can demonstrate links of immune system dysfunction consequences to $\mathrm{CFs}$, is required. While the results of the present study demonstrate a substantial number of GIC and COVID-19 direct impact CFs that overlapped, it was considered that far more overlaps between GIC and COVID-19 were possible using the discovery approach. This was the purpose of the third (discovery) literature that was generated. 
There were three general themes of articles retrieved from the third (discovery) literature associated with potential CFs for impacting COVID-19 indirectly, although not every third literature article retrieved reflected each theme (some articles reflected only one of the themes; some reflected two, and some reflected all three). The first was increasing vulnerability to infectious disease; the second was exacerbating the seriousness of an existing infectious disease; the third was adversely impacting biomarkers that reflected coagulation, hypoxia, etc., as well as biomarkers that reflected immune system dysfunction. All else being equal, the prioritization of the selection of the potential discovery CFs for inclusion in the present study followed the order above.

There is no guarantee that a CF that produces any one of the three adverse effects listed above, or all three simultaneously, will have the same adverse impact for COVID-19. The reasoning for selection is that if the CF had this adverse effect, or a combination of adverse effects, for another infectious disease, there is greater likelihood that it could have a similar effect on COVID-19, all else being equal. The potential COVID-19 adverse effect(s) need(s) to be demonstrated in an experiment/clinical trial.

Myriad types of commonalities between GIC and COVID-19 beyond CF commonality. In 2014, the first author published a study demonstrating theme commonalities between Parkinson's disease (PD; neurodegenerative) and CD (autoimmune) using phrase matching and bibliographic coupling (shared references) between the two disease literatures (50). Due to the strong emphasis on shared references, the commonality of PD and $\mathrm{CD}$ at a more fundamental mechanism level was demonstrated. Combining these two approaches for identifying commonality (CF commonality and bibliographic coupling/phrase matching) could provide deeper understanding at different levels of commonality between GIC and COVID-19.

\section{Data and methods}

Dot-product approach. The streamlined method used to identify common CFs that impact GIC and COVID-19 directly (these are CFs that are found in the core literatures for GIC and COVID-19) for the present study is termed a dot-product approach $(1,2)$. Lists of known toxic substances were aggregated from myriad (mainly) government agencies, and combined with lists of CFs identified in our previous disease studies $(7,8)$. This combination produced a final list of $>13,000$ CFs potentially impacting disease. While this is certainly a large number of potential CFs, it undoubtedly omits additional CFs that a well-resourced study could have identified.

A core literature query was defined for GIC, applied to PubMed, and the resultant retrieval ( $\sim 275,000$ records with abstracts, covering the period between 1990-early 2021) was imported into VantagePoint (VP) text analysis software (www. theVantagePoint.com; V12 Pro/64). This GIC core literature query is shown in Appendix S1. The title and abstract phrases of the retrieved records were parsed in VP, resulting in lists of numerous phrases. The same procedure was followed for the COVID-19 core literature $(\sim 88,000$ records with abstracts, covering the period between 1990-early 2021); the COVID-19 core literature query is also shown in Appendix S1.
The external list of $>13,000$ phrases of potential CFs was intersected with the parsed list of abstract phrases in the GIC and COVID-19 core literatures to generate the subset of the $13,000+$ phrases relevant to each core literature. There were $\sim 4,400$ candidate CFs that impacted GIC directly, and $\sim 2,800$ candidate CFs (candidate means they are potential CFs, but need to be validated as actual CFs) that impacted COVID-19 directly. These two intersected lists of direct impact CFs were compared, and the candidate direct impact CFs in common between GIC and COVID-19 were identified. Approximately 2,250 candidate direct impact CFs in common were identified, albeit some being variants of the same concept. However, this is a very conservative estimate of candidate direct impact CFs in common, for the reasons shown in Appendix S2.

LRD approach. The dot-product approach described above produced CFs that impacted GIC and COVID-19 directly (using articles contained in the core literatures only). However, as the numbers above indicate, there were $\sim 2,150 \mathrm{CFs}$ that impacted GIC directly, but did not impact COVID-19 directly. The myriad reasons for CF underestimation summarized in Appendix S2 could explain this observation, particularly given the nascency of the majority of the COVID-19 core literature relative to the time required to demonstrate $\mathrm{CF}$-disease linkages in laboratory experiments. This led to the decision to include an approach for identifying CFs that impacted COVID-19 indirectly.

One method for identifying indirect impacts of CFs on a given disease is with use of the discovery component of LRDI. This has been used successfully to generate CF discovery in chronic kidney disease (CKD) (8) and Alzheimer's disease (AD) (7). It has also been used to generate treatment discovery (treatment repurposing) for CKD (8) and AD (7), as well as for IBD (34). A variant of this discovery approach was developed for the present study.

In previous studies, patterns of biomarkers, symptoms, etc., in a disease core literature that were associated with that disease were extracted and applied to the larger non-disease literature to identify substances and behaviors that produced these patterns $(7,8)$ (as described in the Introduction). Following the analyses of the retrievals, a number of these substances and behaviors were classified as potential CFs to the disease of interest, and needed to be validated through experiments and/or epidemiological studies. There were no constraints placed on the substances and behaviors.

The present study aimed to select, from the $\sim 2,150$ substances and behaviors, CFs impacting GIC directly and not impacting COVID-19 directly. The study also aimed to ascertain whether evidence existed in the non-COVID-19 literature to validate that at least some of the substances selected could be viewed as candidate CFs for indirect impact of COVID-19 (CF discovery, or CF repurposing, analogous to treatment repurposing). The present study used a modified version of recent discovery queries previously demonstrated (49) that required retrievals to contain the $\mathrm{CF}$ under consideration (this modified version of the discovery query is shown in Appendix S1). For purposes of completeness, this approach was eventually applied to all the CFs selected for display purposes, and the results are presented in Table II.

Selection of candidate common CFs for validation. The phrases in common between GIC and COVID-19 should be 
Table II. Common contributing factors to GIC and COVID-19.

\begin{tabular}{|c|c|c|c|c|c|}
\hline \multirow[b]{2}{*}{ Contributing factor (from dot-product) } & \multirow[b]{2}{*}{ Cat. } & \multirow[b]{2}{*}{ Impact on COV } & \multicolumn{3}{|c|}{ (Refs.) } \\
\hline & & & GIC & $\mathrm{COV}$ & Disc \\
\hline Advanced glycation end products & 1 & $\mathrm{D}$ & (53) & (74) & (75) \\
\hline Alcohol consumption & 1 & $\mathrm{D}$ & (76) & (77) & (78) \\
\hline Circadian disruption/poor sleep & 1 & $\mathrm{D}$ & (79) & $(80)$ & (81) \\
\hline High temperature cooking & 1 & I & (82) & & (83) \\
\hline High-fat diet & 1 & $\mathrm{D}$ & (84) & $(85)$ & (86) \\
\hline Malnutrition & 1 & $\mathrm{D}$ & (87) & (88) & (89) \\
\hline Nitrosamines & 1 & I & (90) & & (91) \\
\hline Red meat & 1 & $\mathrm{D}$ & $(92)$ & (93) & (94) \\
\hline Sedentary/physical inactivity & 1 & $\mathrm{D}$ & (95) & (96) & (97) \\
\hline Smoking & 1 & $\mathrm{D}$ & (98) & (99) & $(100)$ \\
\hline Sodium intake & 1 & $\mathrm{D}$ & $(101)$ & $(102)$ & (103) \\
\hline $\begin{array}{l}\text { Substance abuse/morphine/cocaine/opioids/ } \\
\text { heroin/methamphetamine }\end{array}$ & 1 & $\mathrm{D}$ & (104) & $(105)$ & (106) \\
\hline Vitamin D deficiency & 1 & $\mathrm{D}$ & (107) & $(108)$ & (109) \\
\hline Western diet & 1 & $\mathrm{D}$ & (110) & (111) & (112) \\
\hline Bone marrow transplantation & 2 & $\mathrm{D}$ & (113) & (114) & (115) \\
\hline Liver transplantation & 2 & $\mathrm{D}$ & (116) & (117) & (118) \\
\hline Omeprazole/proton pump inhibitors & 2 & $\mathrm{D}$ & (119) & $(120)$ & (121) \\
\hline Ovariectomy & 2 & $\mathrm{D}$ & $(122)$ & $(123)$ & (124) \\
\hline Radiotherapy & 2 & $\mathrm{D}$ & (125) & (126) & (127) \\
\hline Renal transplantation & 2 & $\mathrm{D}$ & (128) & (129) & (130) \\
\hline Cytomegalovirus & 3 & $\mathrm{D}$ & (131) & $(132)$ & (133) \\
\hline Herpes simplex virus & 3 & $\mathrm{D}$ & (134) & $(135)$ & (136) \\
\hline Mycotoxins & 3 & $\mathrm{D}$ & (137) & $(138)$ & (139) \\
\hline Aluminum & 4 & I & (140) & & (141) \\
\hline Arsenic/As & 4 & $\mathrm{D}$ & $(142)$ & $(143)$ & (144) \\
\hline Asbestos & 4 & I & (145) & & (146) \\
\hline Benzene & 4 & $\mathrm{D}$ & (147) & $(148)$ & (149) \\
\hline Benzidine & 4 & $\mathrm{D}$ & $(150)$ & $(151)$ & $(152)$ \\
\hline Bisphenol A & 4 & $\mathrm{D}$ & (153) & $(154)$ & (155) \\
\hline Cadmium/Cd & 4 & $\mathrm{D}$ & (156) & $(157)$ & $(158)$ \\
\hline Carbon dioxide $/ \mathrm{CO}_{2} / \mathrm{CO}(2)$ & 4 & I & (159) & & $(160)$ \\
\hline Carbon tetrachloride & 4 & I & $(161)$ & & $(162)$ \\
\hline Chlordane & 4 & I & $(163)$ & & (164) \\
\hline Chlorinated drinking water & 4 & $\mathrm{D}$ & $(165)$ & $(166)$ & (167) \\
\hline Chloroform & 4 & I & $(168)$ & & (169) \\
\hline Chlorpyrifos & 4 & I & $(170)$ & & (171) \\
\hline Chromium/Cr & 4 & $\mathrm{D}$ & $(172)$ & $(157)$ & (173) \\
\hline Crude oil & 4 & I & (174) & & $(175)$ \\
\hline Di(2-ethylhexyl) phthalate & 4 & I & (176) & & $(177)$ \\
\hline Heterocyclic amine & 4 & I & (178) & & (179) \\
\hline Ionizing radiation & 4 & $\mathrm{D}$ & $(180)$ & (29) & $(181)$ \\
\hline Mercury/Hg & 4 & $\mathrm{D}$ & (182) & $(157)$ & (183) \\
\hline Microplastics & 4 & I & (184) & & (185) \\
\hline Nanoparticles & 4 & $\mathrm{D}$ & (186) & $(187)$ & (188) \\
\hline Nickel & 4 & I & (189) & & (190) \\
\hline Nitrate & 4 & $\mathrm{D}$ & (191) & $(192)$ & (193) \\
\hline Nitrite & 4 & $\mathrm{D}$ & (194) & $(192)$ & (195) \\
\hline Nitrogen dioxide $/ \mathrm{NO}_{2} / \mathrm{NO}(2)$ & 4 & $\mathrm{D}$ & (196) & $(197)$ & (198) \\
\hline Organochlorines & 4 & I & (199) & & (200) \\
\hline Organophosphates & 4 & $\mathrm{D}$ & $(201)$ & $(202)$ & (203) \\
\hline
\end{tabular}


Table II. Continued.

\begin{tabular}{lccccc}
\hline & & & & \multicolumn{3}{c}{ (Refs.) } \\
\cline { 5 - 6 } Contributing factor (from dot-product) & Cat. & Impact on COV & GIC & COV & Disc \\
\hline Ozone & 4 & I & $(196)$ & & $(204)$ \\
Pb & 4 & D & $(205)$ & $(32)$ & $(206)$ \\
Perfluorooctanoic acid & 4 & I & $(207)$ & & $(208)$ \\
PM(10)/PM10 & 4 & D & $(209)$ & $(210)$ & $(211)$ \\
PM(2.5)/PM2.5 & 4 & D & $(196)$ & $(212)$ & $(213)$ \\
Polychlorinated biphenyls/PCBs & 4 & I & $(199)$ & & $(214)$ \\
Polycyclic aromatic hydrocarbons & 4 & D & $(215)$ & $(216)$ & $(217)$ \\
Silica & 4 & D & $(218)$ & $(219)$ & $(220)$ \\
Talc & 4 & I & $(221)$ & & $(222)$ \\
TCDD (2,3,7,8-tetrachlorodibenzodioxin) & 4 & D & $(223)$ & $(166)$ & $(224)$ \\
Trichloroethylene & 4 & I & $(225)$ & & $(226)$ \\
Chronic stress & 5 & D & $(227)$ & $(228)$ & $(229)$ \\
Restraint stress & 5 & I & $(230)$ & & $(231)$ \\
\hline
\end{tabular}

GIC, gastrointestinal cancer; Cat., category; COV, coronavirus 2019 (COVID-19); D, direct impact; Disc, discovery; I, indirect impact.

viewed as candidate CFs, which must be validated as actual CFs by detailed analysis. There was also the question of how many validated CFs are required to support the hypothesis of common causation between the two diseases. There are two main criteria to be considered in making the selection. The first criterion is the numbers of CFs in common. The second criterion is the importance of the CFs in contributing to the disease.

In the case that the system operation is determined mainly by a few significant factors, as in a number of large and complex systems, then a handful of such significant factors is all that would be required to support the hypothesis. If no such significant factors stand out, then further CFs would be required to support the hypothesis of common cause.

For GIC and COVID-19, there were significant factors that stood out, and these were the foundation of the validation selection process. A balance/trade-off between the two major selection criteria resulted in the selection of 63 common phrases between GIC and COVID-19 to be validated as CFs. These 63 phrases included those deemed most significant and spanning the five-category taxonomy we have developed for classifying modifiable CFs to disease: Lifestyle, iatrogenic, biotoxins, occupational/environmental, psychosocial/socioeconomic (7). Genetics was not included, since the CFs in the current definition were viewed as modifiable, indicating that they were relatively controllable.

Given the shortcomings of the COVID-19 core literature from the perspective of insufficient causation studies (as described above), the present study also included CFs that impacted COVID-19 indirectly. This would also demonstrate the novel CF discovery technique developed for the present study. In total 21 of the 63 candidate CFs were selected as indirect impact CFs and validated as proof of concept. A schematic diagram of the study protocol and approach used is presented in Fig. 2.

\section{Results}

The 63 GIC direct impact CFs in common with the COVID-19 direct and indirect impact CFs selected for validation are presented in Table II. The detailed record excerpts demonstrating the links between the CFs and disease are presented in Appendix S3.

Table II contains six columns. The first (leftmost) column (CF) is the CF that was validated. The second column contains the category to which the CF is assigned (1, lifestyle; 2, iatrogenic; 3, biotoxin; 4, occupational/environmental; and 5 , psychosocial/socioeconomic). The third column signifies whether the impact of the CF on COVID-19 was direct or indirect. The fourth, fifth and sixth columns contain the references that link each $\mathrm{CF}$ to the biomarkers, and are presented in the order of GIC literature, COVID-19 literature and discovery literature. If a CF listed in the first column has no reference listed in the fifth column, then it was not a COVID-19 direct impact $\mathrm{CF}$, and the reference in the sixth column reflects a validated discovery (the listed CF impacts COVID-19 indirectly). If a CF listed in the first column has a reference in the fifth column, then it was a COVID-19 direct impact CF, and the reference in the sixth column reflects a confirmed discovery [it was a validated discovery prior to 2020 , and became a confirmed discovery in 2021 when proof of direct linkage became available in a record(s)].

\section{Discussion}

The results of the present study conclusively demonstrate the wide range of CFs in common between GIC and COVID-19. The next section addresses some of the numerous mechanisms considered responsible for these links, followed by a section that demonstrates how these common $\mathrm{CF}$ results provide the basis for a unified theory of infectious and chronic disease. 


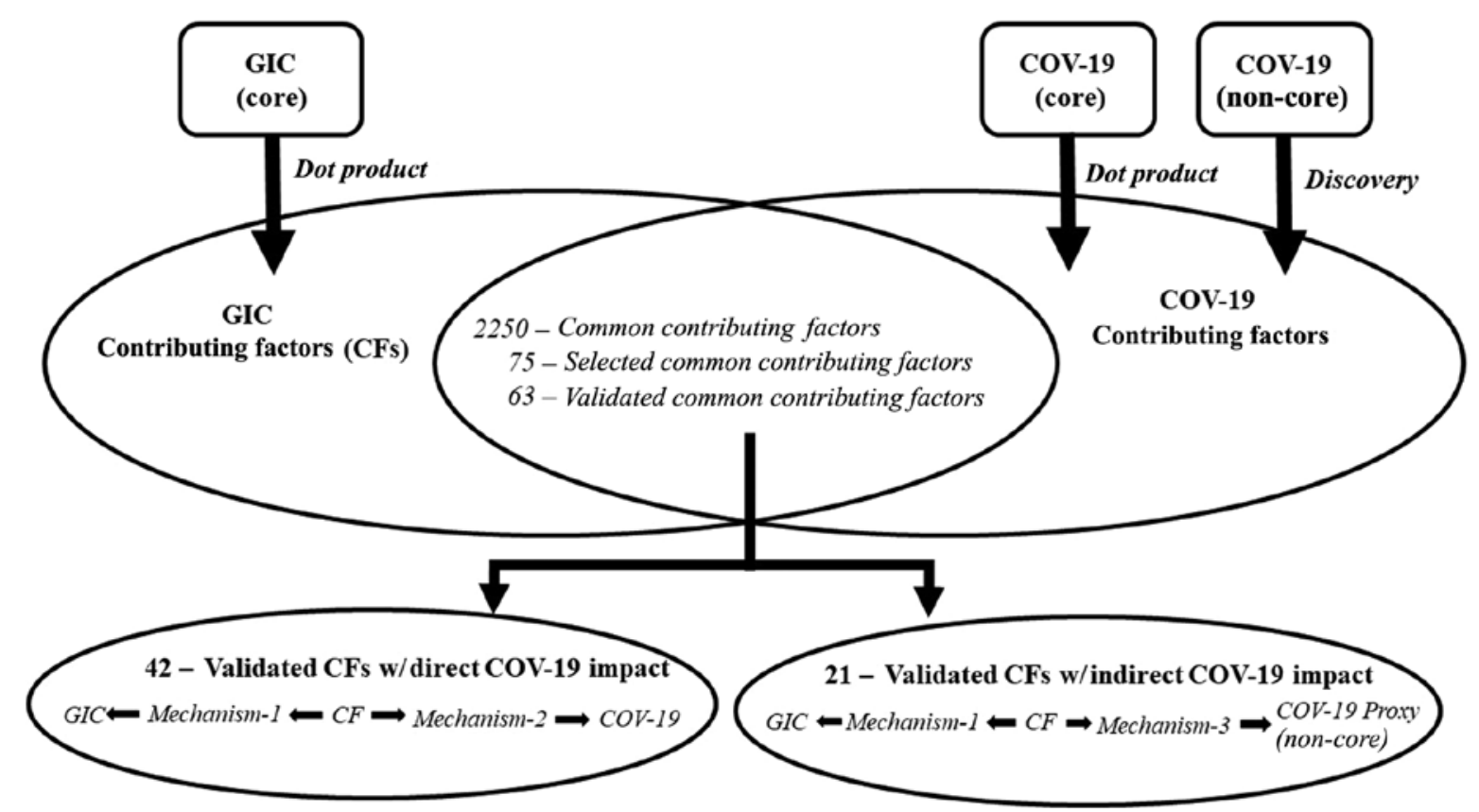

Figure 2. Schematic diagram of the study protocol and approach used to identify the contributing factors common to gastrointestinal cancer (GIC) and COVID-19 (COV-19).

The operational implication of the results is that strengthening the immune system against both infectious and autoimmune diseases requires the discipline to i) remove exposure to a broad range of toxic substances; and ii) eliminate toxic behaviors.

Mechanisms that link CFs with GIC and COVID-19. It would be of interest to determine some of the mechanisms that link CFs identified in the present study with GIC and COVID-19. The following brief analysis examines the role of advanced glycation end products (AGEs), high-fat diets (HFDs), cooked red meat, excessive alcohol consumption and a sedentary lifestyle in contributing to, and/or exacerbating, GIC.

A dietary context appears to contribute to and sustain the global burden of GICs (51). Among the CFs, a main role is played by AGEs that can activate the NLR family pyrin domain containing 3 (NLRP3) inflammasome (52). This not only determines the colonic inflammation environment for carcinogenesis (53), but also impairs innate immune response in macrophages (35), thereby contributing to the tumor escape from innate immunosurveillance $(54,55)$.

A potent carcinogenic stimulus is also provided by HFDs $(55,56)$. Mechanistically, HFDs predispose an inflammatory scenario by inducing a systemic chronic low-grade inflammation (57) characterized by the elevated production of the pro-inflammatory cytokines, IL-1 $\beta$, IL- 6 and TNF- $\alpha$ (58), in the gut. Again, the inflammatory trigger is represented by the activation of the NLRP3 inflammasome (59), with saturated fatty acids favoring NLRP3 inflammasome activation (60) and unsaturated fatty acids impeding NLRP3 activity $(61,62)$.

Another crucial dietary CF in GI carcinogenesis is represented by the consumption of high amounts of cooked red meat. Indeed, consuming red meat equates to introducing hemoglobin and its degradation products, heme and iron, in non-hematopoietic tissues (63). Iron can generate severe oxidative stress via the Fenton reaction, thus causing severe inflammatory pathologies and eventually leading to cancer (63-65). Moreover, the iron load is a crucial factor in colorectal carcinogenesis as it can trigger the macrophage expression of TNF- $\alpha$-converting enzyme (TACE; also known as ADAM17) (66,67). The tolerable iron upper intake level (UL) for adults is $45 \mathrm{mg} /$ day of iron, a level based on gastrointestinal distress as an adverse effect. The median dietary intake of iron is $\sim 16-18 \mathrm{mg} /$ day for males and $12 \mathrm{mg}$ /day for females (https://www.ncbi.nlm.nih.gov/books/NBK222309/).

TACE is a sheddase (membrane-bound enzyme) that cuts and sheds the membrane-bound precursor of TNF- $\alpha$ to its mature soluble form (68). In other words, a cytokine storm is unleashed, given that TNF- $\alpha$ is the master regulator of inflammatory cytokine production (69).

Such a sequence of potent inflammatory events can be further enhanced by alcohol consumption. In fact, the iron-induced oxidative stress and inflammation are potentiated by excessive alcohol abuse that results in further dysregulated iron homeostasis at the hepatic level and heightened TACE induction and activity (66).

In this pathological scenario dominated by inflammation and oxidative stress, a sedentary lifestyle also plays a role. Indeed, sedentary behavior relates to chronic inflammation and colorectal cancer development, while physical activity plays a protective role $(70,71)$. The molecular basis of the protection exerted by physical activity appears to reside in a transcriptional factor, the peroxisome proliferator-activated receptor $\gamma$ co-activator $1 \alpha$ (PGC-1 $\alpha)$, the level of which is enhanced by physical activity (72). In fact, $\mathrm{PGC}-1 \alpha$ regulates proteins involved in the antioxidant defense and lowers the expression of inflammatory markers (73).

On the whole, these five CFs, namely AGEs, HFDs, red meat, alcohol consumption and sedentary behavior, suffice to 
explain much of the 2018 epidemiological data reporting an estimated 4.8 million new cases of GICs and 3.4 million related deaths worldwide, with GI cancers accounting for $26 \%$ of the global cancer incidence and $35 \%$ of all cancer-related deaths (51).

Unified theory of infectious and chronic diseases. The present study is the third one by the first author and colleagues examining the CFs common to COVID-19 and a chronic disease $(1,2)$. As time has proceeded, and the COVID-19 core literature has increased in size, other CFs linked to COVID-19 have emerged and commonality of CFs to chronic disease has increased. This trend is expected to continue.

All three studies have demonstrated the existence of numerous potential CFs common to the two types of disease, and at least 50 common CFs have been validated in each study. Many of the common infectious disease-chronic disease CFs are also common among the three studies. For the CFs that have been validated, myriad common factors include lifestyle (e.g., dietary content, vitamin and mineral deficiencies, food processing and preparation, exercise, sleep, substance abuse, etc.), occupational/environmental (air pollution, water pollution, heavy metals, agrochemicals, occupational chemicals, ionizing and non-ionizing radiations, etc.), and psychosocial/socioeconomic (myriad forms of stress, adverse childhood experiences, isolation, low income, etc.) factors. Iatrogenic factors are mixed; substances/radiations that are beneficial for treating one disease may exacerbate other diseases. Biotoxins are mixed as well, particularly since some viruses associated with disease enhancement are also used as vectors for drug/treatment delivery.

In the case that the majority of the important CFs to COVID-19 are important CFs to the associated chronic diseases examined, as increasingly appears to be the case with the growth of the COVID-19 literature, the question remains of what could be concluded about the similarity of these infectious and chronic diseases.

One important conclusion is that for the prevention of either type of disease, the CFs identified and validated must be eliminated/reduced as broadly, deeply, and rapidly as possible.

A second important conclusion is that, if it is assumed that the symptoms characteristic of either disease represent the host's response to the CFs, the same fundamental disease can have myriad manifestations exhibited through the symptoms. Thus, treating the host's manifestation of the disease (symptoms) is different from treating the disease. The manifestations can be suppressed, but the disease perseveres. Only elimination of the CFs, as outlined in the previous paragraph, has the potential to eliminate the disease (and its associated damages) at its core (assuming that the damages resulting from the disease are not irreversible and the host does not have a strong genetic predisposition to the disease).

There may be treatments for COVID-19 and GIC that overlap; however, there may also be treatments that are antagonistic. As demonstrated in prior sections and the biomedical literature (39-45), inflammatory and coagulation factors exhibit clinical manifestations in both COVID-19 and GIC. Treatments that reduce inflammation and coagulation should be beneficial to both diseases, and could possibly overlap. Conversely, immunosuppressants (used in myriad cancer treatments) tend to increase vulnerability to infectious diseases. In general, if the removal of a potential cause is defined as one type of treatment, then one potential class of overlapping treatments will be the removal of the CFs in common between GIC and COVID-19.

The third conclusion relates to the different external manifestations of disease, even though the CFs have a strong commonality. In the case of the existence of a high commonality between the CFs to GIC and COVID-19, the question would arise as to why one group of individuals manifests COVID-19 symptoms and another group manifests GIC symptoms (although in actuality the vast majority of individuals experiencing the most severe forms of COVID-19 are those with multiple chronic disease comorbidities, exhibiting symptoms of both types of diseases).

There are at least two explanations for this. Individuals have different genetic structures and different predispositions (particularly as regards responses to CFs), and their external manifestations would be expected to differ. Second, CFs have temporal and dosage components (among others), so the $\mathrm{CF}$ 'signature' of each individual differs, even following exposure to the same type of CF. As a simple example, one individual who smokes may develop lung cancer, another may develop $\mathrm{CD}$, another may develop myocardial infarction, another may develop COVID-19 and another may remain healthy. In real-life, individuals are exposed to myriad combinations of CFs. Depending on the complex structure of temporal and dosage components of each $\mathrm{CF}$ and the nature of interactions among CFs, different external manifestations of the exposure combinations would be expected.

It may be possible that the analysis and treatment of these infectious and chronic diseases have been performed using the wrong 'coordinate system'. These diseases have been viewed from the perspective of their external manifestations (symptoms) rather than the perspective of their CFs. When 'coordinates' are switched from symptoms to CFs, and focus is placed on treatments and preventative measures to alter the CFs rather than the symptoms, a unified approach for resolving the dichotomy between these two types of diseases and, most importantly, eliminating their prevalence, may be presented. Obviously, in the case that symptoms become life-threatening or may result in permanent damage, short-term tactical treatments are required; however, for the intermediate or long-term, preventive measures are necessary.

New paradigm required for preventing and treating infectious and chronic diseases. The findings of the present study suggest a need for a paradigmatic shift in medical approaches to disease. The current approach to both infectious and chronic disease in Western medicine is often external-treatment-based (i.e., providing a drug, vaccine, radiation, surgery, etc.) to reduce symptoms without sufficiently addressing the underlying modifiable factors that enabled the disease to emerge. The present study highlights modifiable factors (toxic exposures and behaviors) that contribute to disease pathogenesis via various mechanisms of immune dysfunction, and demonstrates CF commonality between GIC and COVID-19. Eliminating these factors as comprehensively and rapidly as possible is prudent, and perhaps should be pursued in parallel with treatment. 


\section{Acknowledgements}

Not applicable.

\section{Funding}

No funding was received.

\section{Availability of data and materials}

All data generated or analyzed during this study are included in this published article and in the supplementary material.

\section{Authors' contributions}

RNK contributed to the conception of the study, as well as in data analysis and in the writing of the manuscript. MBB participated in data analysis, validation of the results, and in the preparation of the tables. DK participated in data analysis and in the writing of the manuscript. DRS contributed to query development, background development, and in the writing and editing of the manuscript. LK contributed to data analysis, as well as in the study design, and in the writing, and editing of the manuscript. ALP contributed to the conception and design of the study, as well as in the writing and editing of the manuscript. ND contributed to the design of the study, as well as in the drafting, writing and editing of the manuscript. AT contributed to the critical revision of the study, as well as in the design, drafting writing, and editing of the manuscript. DAS contributed to the design of the study, as well as in the revision, writing and editing of the manuscript. RNK and MBB confirm the authenticity of all the raw data. All the authors have read and approved the final version of the manuscript.

\section{Ethics approval and consent to participate}

Not applicable.

\section{Patient consent for publication}

Not applicable.

\section{Competing interests}

DAS is the Editor-in-Chief for the journal, but had no personal involvement in the reviewing process, or any influence in terms of adjudicating on the final decision, for this article. The other authors declare that they have no competing interests.

\section{References}

1. Kostoff RN, Briggs MB, Kanduc D, Porter AL and Buchtel HA: Communicable Diseases are not Communicable! Georgia Institute of Technology. 2020. https://smartech.gatech. edu/handle/1853/63805.

2. Kostoff RN, Briggs MB, Kanduc D, Shores DR, Kovatsi L, Vardavas AI and Porter AL: Common contributing factors to COVID-19 and inflammatory bowel disease. Toxicol Rep 8 : 1616-1637, 2021

3. Kostoff RN, Briggs MB, Porter AL, Hernandez AF, Abdollahi M, Aschner $\mathrm{M}$ and Tsatsakis A: The under-reported role of toxic substance exposures in the COVID-19 pandemic. Food Chem Toxicol 145: 111687, 2020 .
4. Kostoff RN, Kanduc D, Porter AL, Shoenfeld Y, Calina D, Briggs MB, Spandidos DA and Tsatsakis A: Vaccine- and natural infection-induced mechanisms that could modulate vaccine safety. Toxicol Rep 7: 1448-1458, 2020.

5. Gorji A and Khaleghi Ghadiri M: Potential roles of micronutrient deficiency and immune system dysfunction in the coronavirus disease 2019 (COVID-19) pandemic. Nutrition 82: 111047, 2021.

6. Kostoff RN, Goumenou M and Tsatsakis A: The role of toxic stimuli combinations in determining safe exposure limits. Toxicol Rep 5: 1169-1172, 2018.

7. Kostoff RN, Porter AL and Buchtel HA: Prevention and reversal of Alzheimer's disease: treatment protocol. Georgia Institute of Technology. 2018. https://smartech.gatech. edu/handle/1853/59311.

8. Kostoff RN and Patel U: Literature-related discovery and innovation: Chronic kidney disease. Technol Forecast Soc Change 91: 341-351, 2015.

9. Liu J, Xie W, Wang Y, Xiong Y, Chen S, Han J and Wu Q: A comparative overview of COVID-19, MERS and SARS: Review article. Int J Surg 81: 1-8, 2020.

10. Zhang YY, Li BR and Ning BT: The Comparative Immunological Characteristics of SARS-CoV, MERS-CoV, and SARS-CoV-2 Coronavirus Infections. Front Immunol 11: 2033, 2020.

11. Kim ES, Choe PG, Park WB, Oh HS, Kim EJ, Nam EY, $\mathrm{Na}$ SH, Kim M, Song KH, Bang JH, et al: Clinical Progression and Cytokine Profiles of Middle East Respiratory Syndrome Coronavirus Infection. J Korean Med Sci 31: 1717-1725, 2016.

12. Qin C, Zhou L, Hu Z, Zhang S, Yang S, Tao Y, Xie C, Ma K, Shang K, Wang W and Tian D-S: Dysregulation of Immune Response in Patients With Coronavirus 2019 (COVID-19) in Wuhan, China. Clin Infecti Dis 71: 762-768, 2020

13. Huang C, Wang Y, Li X, Ren L, Zhao J, Hu Y, Zhang L, Fan G, Xu J, Gu X, et al: Clinical features of patients infected with 2019 novel coronavirus in Wuhan, China. Lancet 395: 497-506, 2020.

14. Liu Y, Yang Y, Zhang C, Huang F, Wang F, Yuan J, Wang Z, Li J, Li J, Feng C, et al: Clinical and biochemical indexes from 2019-nCoV infected patients linked to viral loads and lung injury. Sci China Life Sci 63: 364-374, 2020.

15. Mo P, Xing Y, Xiao Y, Deng L, Zhao Q, Wang H, Xiong Y, Cheng Z, Gao S, Liang K, et al: Clinical characteristics of refractory COVID-19 pneumonia in Wuhan, China. Clin Infect Dis: ciaa270, 2020

16. Qian GQ, Yang NB, Ding F, Ma AHY, Wang ZY, Shen YF, Shi CW, Lian X, Chu JG, Chen L, et al: Epidemiologic and clinical characteristics of 91 hospitalized patients with COVID-19 in Zhejiang, China: a retrospective, multi-centre case series. QJM-Int J Med 113: 474-481, 2020.

17. NaturePortfolio: Gastrointestinal cancer. https://www.nature. com/subjects/gastrointestinal-cancer. Accessed March 21, 2021.

18. National Institutes of Health: Gastrointestinal Neoplasms. https://www.ncbi.nlm.nih.gov/mesh/?term=GASTROINTESTI NAL+NEOPLASMS). Accessed March 24, 2021

19. Sung H, Ferlay J, Siegel RL, Laversanne M, Soer jomataram I, Jemal A and Bray F: Global Cancer Statistics 2020: GLOBOCAN Estimates of Incidence and Mortality Worldwide for 36 Cancers in 185 Countries. CA Cancer J Clin 71: 209-249, 2021.

20. Cancer Stat Facts: Colorectal Cancer: National Cancer Institute Surveillance, Epidemoiology, and End Results Program. https://seer.cancer.gov/statfacts/html/common.html. Accessed March 3, 2021.

21. Yusefi AR, Bagheri Lankarani K, Bastani P, Radinmanesh M and Kavosi Z: Risk Factors for Gastric Cancer: A Systematic Review. Asian Pac J Cancer Prev 19: 591-603, 2018.

22. Poorolajal J, Moradi L, Mohammadi Y, Cheraghi Z and Gohari-Ensaf F: Risk factors for stomach cancer: A systematic review and meta-analysis. Epidemiol Health 42: e2020004, 2020.

23. Castro C, Peleteiro B and Lunet N: Modifiable factors and esophageal cancer: Asystematic review of published meta-analyses. J Gastroenterol 53: 37-51, 2018.

24. Lichtenstern CR, Ngu RK, Shalapour S and Karin M: Immunotherapy, Inflammation and Colorectal Cancer. Cells 9: 618,2020

25. Marmol I, Sanchez-de-Diego C, Pradilla Dieste A, Cerrada E and Rodriguez Yoldi MJ: Colorectal Carcinoma: A General Overview and Future Perspectives in Colorectal Cancer. Int $\mathbf{J}$ Mol Sci 18: 197, 20017.

26. World Cancer Research Fund/American Institute for Cancer Research: Diet, Nutrition, Physical Activity and Cancer: A Global Perspective. Continuous Update Project Expert Report 2018. www.dietandcancerreport.org. 
27. Murphy N, Jenab $M$ and Gunter MJ: Adiposity and gastrointestinal cancers: Epidemiology, mechanisms and future directions. Nat Rev Gastroenterol Hepatol 15: 659-670, 2018.

28. Zhou E and Rifkin S: Colorectal Cancer and Diet: Risk Versus Prevention, Is Diet an Intervention? Gastroenterol Clin North Am 50: 101-111, 2021.

29. Tsatsakis A, Petrakis D, Nikolouzakis TK, Docea AO, Calina D, Vinceti M, Goumenou M, Kostoff RN, Mamoulakis C, Aschner M and Hernández AF: COVID-19, an opportunity to reevaluate the correlation between long-term effects of anthropogenic pollutants on viral epidemic/pandemic events and prevalence. Food Chem Toxicol 141: 111418, 2020.

30. Margină D, Ungurianu A, Purdel C, Tsoukalas D, Sarandi E, Thanasoula M, Tekos F, Mesnage R, Kouretas D and Tsatsakis A: Chronic Inflammation in the Context of Everyday Life: Dietary Changes as Mitigating Factors. Int J Environ Res Public Health 17: 4135, 2020.

31. Calina D, Hartung T, Mardare I, Mitroi M, Poulas K, Tsatsakis A Rogoveanu I and Docea AO: COVID-19 pandemic and alcohol consumption: Impacts and interconnections. Toxicol Rep 8: 529-535, 2021

32. Skalny AV,Lima TRR, Ke T,Zhou JC, Bornhorst J, Alekseenko SI, Aaseth J, Anesti O, Sarigiannis DA, Tsatsakis A, et al: Toxic metal exposure as a possible risk factor for COVID-19 and other respiratory infectious diseases. Food Chem Toxicol 146: 111809, 2020.

33. Margină D, Ungurianu A, Purdel C, Nitulescu GM, Tsoukalas D, Sarandi E, Thanasoula M, Burykina TI, Tekos F, Buha A, et al: Analysis of the intricate effects of polyunsaturated fatty acids and polyphenols on inflammatory pathways in health and disease. Food Chem Toxicol 143: 111558, 2020.

34. Skalny AV, Timashev PS, Aschner M, Aaseth J, Chernova LN, Belyaev VE, Grabeklis AR, Notova SV, Lobinski R, Tsatsakis A, et al: Serum Zinc, Copper, and Other Biometals Are Associated with COVID-19 Severity Markers. Metabolites 11: $244,2021$.

35. Lee JK, Shin JH, Gwag BJ and Choi EJ: Iron accumulation promotes TACE-mediated TNF- $\alpha$ secretion and neurodegeneration in a mouse model of ALS. Neurobiol Dis 80: 63-69, 2015.

36. Menghini R, Fiorentino L, Casagrande V, Lauro R and Federici M: The role of ADAM17 in metabolic inflammation. Atherosclerosis 228: 12-17, 2013.

37. Winterbourn CC: Toxicity of iron and hydrogen peroxide: The Fenton reaction. Toxicol Lett 82-83: 969-974, 1995.

38. Yilmaz B and Li H: Gut Microbiota and Iron: The Crucial Actors in Health and Disease. Pharmaceuticals (Basel) 11: 98, 2018

39. Del Valle DM, Kim-Schulze S, Huang HH, Beckmann ND, Nirenberg S, Wang B, Lavin Y, Swartz TH, Madduri D, Stock A, et al: An inflammatory cytokine signature predicts COVID-19 severity and survival. Nat Med 26: 1636-1643, 2020.

40. Rad F, Dabbagh A, Dorgalaleh A and Biswas A: The Relationship between Inflammatory Cytokines and Coagulopathy in Patients with COVID-19. J Clin Med 10: 2020, 2021.

41. Sriram K and Insel PA: Inflammation and thrombosis in COVID-19 pathophysiology: Proteinase-activated and purinergic receptors as drivers and candidate therapeutic targets. Physiol Rev 101: 545-567, 2021.

42. Reitsma PH and Rosendaal FR: Activation of innate immunity in patients with venous thrombosis: The Leiden Thrombophilia Study. J Thromb Haemost 2: 619-622, 2004.

43. Lu W, Pan K, Zhang L, Lin D, Miao X and You W: Genetic polymorphisms of interleukin (IL)-1B, IL-1RN, IL-8, IL-10 and tumor necrosis factor alpha\} and risk of gastric cancer in a Chinese population. Carcinogenesis 26: 631-636, 2005.

44. Oshima H, Ishikawa T, Yoshida GJ, Naoi K, Maeda Y, Naka K, Ju X, Yamada Y, Minamoto T, Mukaida N, et al: TNF- $\alpha / T N F R 1$ signaling promotes gastric tumorigenesis through induction of Noxo1 and Gna14 in tumor cells. Oncogene 33: 3820-3829, 2014

45. Roselli M, Ferroni P, Rolfo C, Peeters M, Palmirotta R, Formica V, Ludovici G, Laudisi A, De Marchis ML, La Farina F, et al: TNF- $\alpha$ gene promoter polymorphisms and risk of venous thromboembolism in gastrointestinal cancer patients undergoing chemotherapy. Ann Oncol 24: 2571-2575, 2013.

46. Kostoff RN, Block JA, Solka JL, Briggs MB, Rushenberg RL, Stump JA, Johnson D, Lyons TJ and Wyatt JR: Literature-Related Discovery. Annu Rev Inf Sci Technol 43: 241-285, 2009.

47. Kostoff RN: Literature-related discovery and innovation - update. Technol Forecast Soc Change 79: 789-800, 2012.

48. Kostoff RN, Briggs MB and Shores DR: Treatment repurposing for inflammatory bowel disease using literature-related discovery and innovation. World J Gastroenterol 26: 4889-4899, 2020.
49. Kostoff RN: Treatment Repurposing using Literature-related Discovery. J Scientometr Res 8: S74-S84, 2019.

50. Kostoff RN: Literature-related discovery: common factors for Parkinson's Disease and Crohn's Disease. Scientometrics 100 623-657, 2014.

51. Arnold M, Abnet CC, Neale RE, Vignat J, Giovannucci EL, McGlynn KA and Bray F: Global Burden of 5 Major Types of Gastrointestinal Cancer. Gastroenterology 159: 335-349, 2020.

52. Kong X, Lu AL, Yao XM, Hua Q, Li XY, Qin L, Zhang HM, Meng GX and Su Q: Activation of NLRP3 Inflammasome by Advanced Glycation End Products Promotes Pancreatic Islet Damage. Oxid Med Cell Longev 2017: 9692546, 2017

53. Geicu OI, Stanca L, Voicu SN, Dinischiotu A, Bilteanu L, Serban AI and Calu V: Dietary AGEs involvement in colonic inflammation and cancer: insights from an in vitro enterocyte model. Sci Rep 10: 2574, 2020.

54. Son S, Hwang I, Han SH, Shin JS, Shin OS and Yu JW: Advanced glycation end products impair NLRP3 inflammasome-mediated innate immune responses in macrophages. J Biol Chem 292: 20437-20448, 2017.

55. Wilczynski JR and Duechler M: How do Tumors Actively Escape from Host Immunosurveillance? Arch Immunol Ther Exp (Warsz) 58: 435-448, 2010

56. Kim M and Park K: Dietary Fat Intake and Risk of Colorectal Cancer: A Systematic Review and Meta-Analysis of Prospective Studies. Nutrients 10: 1963, 2018.

57. Padidar S, Farquharson AJ, Williams LM, Kearney R, Arthur JR and Drew JE: High-fat diet alters gene expression in the liver and colon: links to increased development of aberrant crypt foci. Dig Dis Sci 57: 1866-1874, 2012.

58. Han J, Jiang Y, Liu X, Meng Q, Xi Q, Zhuang Q, Han Y, Gao Y, Ding $Q$ and Wu G: Dietary Fat Intake and Risk of Gastric Cancer: A Meta-Analysis of Observational Studies. PLoS One 10: e0138580, 2015.

59. Duan Y, Zeng L, Zheng C, Song B, Li F, Kong X and Xu K: Inflammatory Links Between High Fat Diets and Diseases. Front Immunol 9: 2649, 2018.

60. Fujiyama Y, Hokari R, Miura S, Watanabe C, Komoto S, Oyama T, Kurihara C, Nagata $\mathrm{H}$ and Hibi T: Butter feeding enhances TNF- $\alpha$ production from macrophages and lymphocyte adherence in murine small intestinal microvessels. J Gastroenterol Hepatol 22: 1838-1845, 2007.

61. Ralston JC, Lyons CL, Kennedy EB, Kirwan AM and Roche HM: Fatty Acids and NLRP3 Inflammasome-Mediated Inflammation in Metabolic Tissues. Stover PJ and Balling R (eds). Annu Rev Nutrition 37: 77-102, 2017.

62. Karasawa T, Kawashima A, Usui-Kawanishi F, Watanabe S, Kimura H, Kamata R, Shirasuna K, Koyama Y, Sato-Tomita A, Matsuzaka T, et al: Saturated Fatty Acids Undergo Intracellular Crystallization and Activate the NLRP3 Inflammasome in Macrophages. Arterioscler Thromb Vasc Biol 38: 744-756, 2018.

63. Kruger $C$ and Zhou Y: Red meat and colon cancer: A review of mechanistic evidence for heme in the context of risk assessment methodology. Food Chem Toxicol 118: 131-153, 2018.

64. Sun H, Zhang C, Cao S, Sheng T, Dong N and Xu Y: Fenton reactions drive nucleotide and ATP syntheses in cancer. J Mol Cell Biol 10: 448-459, 2018.

65. Toyokuni S: Iron and carcinogenesis: From Fenton reaction to target genes. Redox Rep 7: 189-197, 2002.

66. Chua ACG, Klopcic B, Lawrance IC, Olynyk JK and Trinder D: Iron: An emerging factor in colorectal carcinogenesis. World J Gastroenterol 16: 663-672, 2010.

67. Maras JS, Das S, Sharma S, Sukriti S, Kumar J, Vyas AK Kumar D, Bhat A, Yadav G, Choudhary MC, et al: Iron-Overload triggers ADAM-17 mediated inflammation in Severe Alcoholic Hepatitis. Sci Rep 8: 10264, 2018.

68. Moss ML, Jin SLC, Milla ME, Burkhart W, Carter HL, Chen WJ, Clay WC, Didsbury JR, Hassler D, Hoffman CR, et al: Cloning of a disintegrin metalloproteinase that processes precursor tumour-necrosis factor-alpha. Nature 385: 733-736, 1997.

69. Parameswaran N and Patial S: Tumor Necrosis Factor- $\alpha$ Signaling in Macrophages. Crit Rev Eukaryot Gene Expr 20: 87-103, 2010.

70. Derry MM, Raina K, Agarwal C and Agarwal R: Identifying molecular targets of lifestyle modifications in colon cancer prevention. Front Oncol 2013; 3: 119, 2013.

71. Durko L and Malecka-Panas E: Lifestyle Modifications and Colorectal Cancer. Curr Colorectal Cancer Rep 10: 45-54, 2014.

72. Handschin C and Spiegelman BM: The role of exercise and PGC1 alpha in inflammation and chronic disease. Nature 454: 463-469, 2008 
73. Olesen J, Kiilerich K and Pilegaard H: PGC-1 alpha-mediated adaptations in skeletal muscle. Pflugers Arch 460: 153-162, 2010.

74. Holly JMP, Biernacka K, Maskell N and Perks CM: Obesity, Diabetes and COVID-19: An Infectious Disease Spreading From the East Collides With the Consequences of an Unhealthy Western Lifestyle. Front Endocrinol (Lausanne) 11: 582870, 2020.

75. Traore K, Arama C, Medebielle M, Doumbo O and Picot S: Do advanced glycation end- products play a role in malaria susceptibility? Parasite 23: 15, 2016.

76. Na H-K and Lee JY: Molecular Basis of Alcohol-Related Gastric and Colon Cancer. Int J Mol Sci 18: 1116, 2017.

77. Bailey KL, Samuelson DR and Wyatt TA: Alcohol use disorder: A pre-existing condition for COVID-19? Alcohol 90: 11-17, 2021

78. Arvers P: Alcohol consumption and lung damage: Dangerous relationships. Rev Mal Respir 35: 1039-1049, 2018.

79. Lin CL, Liu TC, Wang YN, Chung CH and Chien WC: The Association Between Sleep Disorders and the Risk of Colorectal Cancer in Patients: A Population-based Nested Case-Control Study. In Vivo 33: 573-579, 2019.

80. Silva FRD, Guerreiro RC, Andrade HA, Stieler E, Silva A and de Mello MT: Does the compromised sleep and circadian disruption of night and shiftworkers make them highly vulnerable to 2019 coronavirus disease (COVID-19)? Chronobiol Int 37 : 607-617, 2020.

81. Rosselot AE, Hong CI and Moore SR: Rhythm and bugs: circadian clocks, gut microbiota, and enteric infections. Curr Opin Gastroenterol 32: 7-11, 2016.

82. Sinha R and Rothman N: Role of well-done, grilled red meat, heterocyclic amines (HCAs) in the etiology of human cancer. Cancer Lett 143: 189-194, 1999.

83. Jaarin K, Mustafa MR and Leong XF: The effects of heated vegetable oils on blood pressure in rats. Clinics 66: 2125-2132, 2011.

84. Ocvirk S, Wilson AS, Appolonia CN, Thomas TK and O'Keefe SJD: Fiber, Fat, and Colorectal Cancer: New Insight into Modifiable Dietary Risk Factors. Curr Gastroenterol Rep 21: 62-62, 2019.

85. Batchu SN, Kaur H, Yerra VG, Advani SL, Kabir MG, Liu Y, Klein T and Advani A: Lung and Kidney ACE2 and TMPRSS2 in Renin-Angiotensin System Blocker-Treated Comorbid Diabetic Mice Mimicking Host Factors That Have Been Linked to Severe COVID-19. Diabetes 70: 759-771, 2021.

86. Las Heras V, Clooney AG, Ryan FJ, Cabrera-Rubio R, Casey PG Hueston CM, Pinheiro J, Rudkin JK, Melgar S, Cotter PD, et al: Short-term consumption of a high-fat diet increases host susceptibility to Listeria monocytogenes infection. Microbiome 7: 7 , 2019.

87. Berlau J, Glei M and Pool-Zobel B: Colon cancer risk factors from nutrition. Anal Bioanal Chem 378: 737-743, 2004.

88. Rouget A, Vardon-Bounes F, Lorber P, Vavasseur A, Marion O, Marcheix B, Lairez O, Balardy L, Fourcade O, Conil JM, et al: Prevalence of malnutrition in coronavirus disease 19: The NUTRICOV study. Br J Nutr 126: 1296-1303, 2021.

89. Taylor AK, Cao W, Vora KP, De La Cruz J, Shieh WJ, Zaki SR, Katz JM, Sambhara S and Gangappa S: Protein Energy Malnutrition Decreases Immunity and Increases Susceptibility to Influenza Infection in Mice. J Infect Dis 207: 501-510, 2013.

90. Pillay V, Isaacson C, Mothobi P, Hale M, Tomar LK, Tyagi C, Altini M, Choonara YE and Kumar P: Carcinogenic nitrosamines in traditional beer as the cause of oesophageal squamous cell carcinoma in black South Africans. S Afr Med J 105: 656-658, 2015.

91. Thomas P, Fugmann R, Aranyi C, Barbera P, Gibbons R and Fenters J: The effect of dimethylnitrosamine on host resistance and immunity. Toxicol Appl Pharmacol 77: 219-229, 1985.

92. Seiwert N, Heylmann D, Hasselwander S and Fahrer J: Mechanism of colorectal carcinogenesis triggered by heme iron from red meat. Biochim Biophys Acta Rev Cancer 1873: 188334 2020.

93. Kamyari N, Soltanian AR, Mahjub H and Moghimbeigi A: Diet, Nutrition, Obesity, and Their Implications for COVID-19 Mortality: Development of a Marginalized Two-Part Model for Semicontinuous Data. JMIR Public Health Surveill 7: e22717, 2021.

94. Tappel A: Heme of consumed red meat can act as a catalyst of oxidative damage and could initiate colon, breast and prostate cancers, heart disease and other diseases. Med Hypotheses 68: $562-564,2007$
95. Kerr J, Anderson C and Lippman SM: Physical activity, sedentary behaviour, diet, and cancer: an update and emerging new evidence. Lancet Oncol 18: E457-E471, 2017.

96. Hamer M, Kivimaki M, Gale CR and Batty GD: Lifestyle Risk Factors for Cardiovascular Disease in Relation to COVID-19 Hospitalization: A Community-Based Cohort Study of 387,109 Adults in UK. medRxiv: May 13, 2020 (Epub ahead of print) doi: $10.1101 / 2020.05 .09 .20096438$

97. Stravinskas Durigon T, MacKenzie B, Carneiro Oliveira-Junior M, Santos-Dias A, De Angelis K, Malfitano C, Kelly da Palma R, Moreno Guerra J,Damaceno-Rodrigues NR, Garcia CaldiniE, et al: Aerobic Exercise Protects from Pseudomonas aeruginosa-Induced Pneumonia in Elderly Mice. J Innate Immun 10: 279-290, 2018

98. Dekker E, Tanis PJ, Vleugels JLA, Kasi PM and Wallace MB Colorectal cancer. Lancet 394: 1467-1480, 2019.

99. Rahman A and Sathi NJ: Risk factors of the severity of COVID-19: A meta-analysis. Int J Clin Pract 75: e13916, 2021.

100.Duffney PF, Embong AK, McGuire CC, Thatcher TH, Phipps RP and Sime PJ: Cigarette smoke increases susceptibility to infection in lung epithelial cells by upregulating caveolin-dependent endocytosis. PLoS One 15: e0232102, 2020.

101. Zhang Z and Zhang X: Salt Taste Preference, Sodium Intake and Gastric Cancer in China. Asian Pac J Cancer Prev 12: 1207-1210, 2011

102. Post A, Dullaart RPF and Bakker SJL: Is low sodium intake a risk factor for severe and fatal COVID-19 infection? Eur J Int Med 75: 109, 2020.

103. Targonski R, Sadowski J,Price S and Targonski R: Sodium-induced inflammation-an invisible player in resistant hypertension. Hypertension Res 43: 629-633, 2020.

104. Gholipour M, Islami F, Roshandel G, Khoshnia M, Badakhshan A, Moradi A and Malekzadeh R: Esophageal Cancer in Golestan Province, Iran: A Review of Genetic Susceptibility and Environmental Risk Factors. Middle East J Dig Dis 8: 249-266, 2016.

105. Baillargeon J, Polychronopoulou E, Kuo YF and Raji MA: The Impact of Substance Use Disorder on COVID-19 Outcomes. Psychiatr Serv 72: 578-581, 2021.

106. Yang L, Chen X, Simet SM, Hu G, Cai Y, Niu F, Kook Y and Buch SJ: Reactive Oxygen Species/Hypoxia-Inducible Factor-1 alpha/Platelet-Derived Growth Factor-BB Autocrine Loop Contributes to Cocaine-Mediated Alveolar Epithelial Barrier Damage. Am J Respir Cell Mol Biol 55: 736-748, 2016.

107. Pereira F, Jesus Larriba M and Munoz A: Vitamin D and colon cancer. Endocr Relat Cancer 19: R51-R71, 2012.

108. Meltzer DO, Best TJ, Zhang H, Vokes T, Arora V and Solway J: Association of Vitamin D Status and Other Clinical Characteristics With COVID-19 Test Results. JAMA Netw Open 3: e2019722, 2020.

109. Mandell EW, Ryan S, Seedorf GJ, Gonzalez T, Smith BJ, Fleet JC and Abman SH: Maternal Vitamin D Deficiency Causes Sustained Impairment of Lung Structure and Function and Increases Susceptibility to Hyperoxia-induced Lung Injury in Infant Rats. Am J Respir Cell Mol Biol 63: 79-91, 2020.

110. Xie Y, Zhao Y, Shi L, Li W, Chen K, Li M, Chen X, Zhang H, Li T, Matsuzawa-Ishimoto Y, et al: Gut epithelial TSC1/mTOR controls RIPK3-dependent necroptosis in intestinal inflammation and cancer. J Clin Invest 130: 2111-2128, 2020.

111. Butler MJ and Barrientos RM: The impact of nutrition on COVID-19 susceptibility and long-term consequences. Brain Behav Immun 87: 53-54, 2020.

112. Kramer B, França LM, Zhang Y, Paes AMA, Gerdes AM and Carrillo-Sepulveda MA: Western diet triggers Toll-like receptor 4 signaling-induced endothelial dysfunction in female Wistar rats. Am J Physiol Heart Circ Physiol 315: H1735-H1747, 2018.

113. Worthley DL, Ruszkiewicz A, Davies R, Moore S, Nivison-Smith I, Bik To L, Browett P, Western R, Durrant S, So J, et al: Human Gastrointestinal Neoplasia-Associated Myofibroblasts Can Develop from Bone Marrow-Derived Cells Following Allogeneic Stem Cell Transplantation. Stem Cells 27: 1463-1468, 2009.

114. Huang J, Lin H, Wu Y, Fang Y, Kumar R, Chen G and Lin S: COVID-19 in posttransplant patients-report of 2 cases. AmJ Transplant 20: 1879-1881, 2020.

115. Gowdy KM, Martinu T, Nugent JL, Manzo ND, Zhang HL, Kelly FL, Holtzman MJ and Palmer SM: Impaired CD8(+) T cell immunity after allogeneic bone marrow transplantation leads to persistent and severe respiratory viral infection. Transplant Immunol 32: 51-60, 2015. 
116. Gong CS, Yoo MW, Kim BS, Hwang S, Kim KH, Yook JH, Kim BS and Lee SG: De Novo Gastric Cancer After Liver Transplantation. Ann Transplant 21: 386-391, 2016.

117. Garrido I, Liberal R and Macedo G: Review article: COVID-19 and liver disease-what we know on 1st May 2020. Aliment Pharmacol Ther 52: 267-275, 2020.

118. Laici C, Gamberini L, Bardi T, Siniscalchi A, Reggiani MLB and Faenza S: Early infections in the intensive care unit after liver transplantation-etiology and risk factors: A single-center experience. Transpl Infect Dis 20: e12834, 2018.

119. Cheung KS, Chan EW, Wong AYS, Chen L, Wong ICK and Leung WK: Long-term proton pump inhibitors and risk of gastric cancer development after treatment for Helicobacter pylori: A population-based study. Gut 67: 28-35, 2018.

120. Almario CV, Chey WD and Spiegel BMR: Increased Risk of COVID-19 Among Users of Proton Pump Inhibitors. Am J Gastroenterol 115: 1707-1715, 2020.

121. Canani RB, Cirillo P, Roggero P, Romano C, Malamisura B, Terrin G, Passariello A, Manguso F, Morelli L, Guarino A; Working Group on Intestinal Infections of the Italian Society of Pediatric Gastroenterology, Hepatology and Nutrition (SIGENP): Therapy with gastric acidity inhibitors increases the risk of acute gastroenteritis and community-acquired pneumonia in children. Pediatrics 117: e817-e820, 2006.

122. Roshan MHK, Tambo A and Pace NP: The role of testosterone in colorectal carcinoma: pathomechanisms and open questions. EPMA J 7: 22, 2016.

123. Erfinanda L, Ravindran K, Kohse F, Gallo K, Preissner R, Walther T and Kuebler WM: Oestrogen-mediated upregulation of the Mas receptor contributes to sex differences in acute lung injury and lung vascular barrier regulation. Eur Respirat J 57: 2000921, 2021.

124. Thabet HS, Thabet SS, Ali NM and Ahmed NS: Effects of ovariectomy and thyroidectomy on course and outcome of Trichinella spiralis infection rat. Egypt Soc Parasitol 38: 29-46, 2008.

125. Sheridan J, Tosetto M, Gorman J, O'Donoghue D, Sheahan K, Hyland J, Mulcahy H, Gibbons D and O'Sullivan J: Effects of radiation on levels of DNA damage in normal non-adjacent mucosa from colorectal cancer cases. J Gastrointest Cancer 44: 41-45, 2013.

126. Song K, Gong H, Xu B, Dong X, Li L, Hu W, Wang Q, Xie Z, Rao Z, Luo Z, et al: Association between recent oncologic treatment and mortality among patients with carcinoma who are hospitalized with COVID-19: A multicenter study. Cancer 127: 437-448, 2021.

127. Gowda SSN, Raviraj R, Nagarajan D and Zhao W: Radiation-induced lung injury: impact on macrophage dysregulation and lipid alteration - a review. Immunopharmacol Immunotoxicol 41: 370-379, 2019.

128. Balhareth A, Reynolds IS, Solon JG, Harte EG, Boland F, O'Sullivan JM, Burke JP, Little D and McNamara DA: Thirty-seven-year Population-based Study of Colorectal Cancer Rates in Renal Transplant Recipients in Ireland. Transplant Proc 50: 3434-3439, 2018.

129. Caillard S, Chavarot N, Francois H, Matignon M, Greze C, Kamar N, Gatault P, Thaunat O, Legris T, Frimat L, et al: Is COVID-19 infection more severe in kidney transplant recipients? Am J Transplant 21: 1295-1303, 2021.

130. Kinnunen S, Karhapaa P, Juutilainen A, Finne P and Helantera I: Secular Trends in Infection-Related Mortality after Kidney Transplantation. Clin J Am Soc Nephrol 13: 755-762, 2018.

131. Cai ZZ, Xu JG, Zhou YH, Zheng JH, Lin KZ, Zheng SZ, Ye MS, He Y, Liu CB and Xue ZX: Human cytomegalovirus-encoded US28 may act as a tumor promoter in colorectal cancer. World J Gastroenterol 22: 2789-2798, 2016.

132. Moss P: 'The ancient and the new': is there an interaction between cytomegalovirus and SARS-CoV-2 infection? Immun Ageing 17: 14, 2020

133. Zhou W, Xi D, Shi Y, Wang L, Zhong H, Huang Z, Liu Y, Tang Y, Lu N, Wang Y, et al: MicroRNA-1929-3p participates in murine cytomegalovirus-induced hypertensive vascular remodeling through Ednra/NLRP3 inflammasome activation. Int J Mol Med 47: 719-731, 2021.

134. Chang $C$ and Worrell SG: Viruses and esophageal cancer. Dis Esophagus 33: doaa036, 2020

135. Shrock E, Fujimura E, Kula T, Timms RT, Lee IH, Leng Y, Robinson ML, Sie BM, Li MZ, Chen Y, et al: Viral epitope profiling of COVID-19 patients reveals cross-reactivity and correlates of severity. Science 370: eabd4250, 2020.
136. Sartori E, Calistri A, Salata C, Del Vecchio C, Palù G and Parolin C: Herpes simplex virus type 2 infection increases human immunodeficiency virus type 1 entry into human primary macrophages. Virol J 8: 266, 2011.

137. Wu F, Groopman JD and Pestka JJ: Public Health impacts of foodborne mycotoxins. Klaenhammer TR (ed). Annu Rev Food Sci Technol 5: 351-372, 2014.

138. Liu D, Ge L, Wang Q, Su J, Chen X, Wang C and Huang K: Low-level contamination of deoxynivalenol: A threat from environmental toxins to porcine epidemic diarrhea virus infection. Environ Int 143: 105949, 2020.

139. Li M, Harkema JR, Islam Z, Cuff CF and Pestka JJ: T-2 toxin impairs murine immune response to respiratory reovirus and exacerbates viral bronchiolitis. Toxicol Appl Pharmacol 217: $76-85,2006$

140. Jeong CH, Kwon HC, Cheng WN, Kim DH, Choi Y and Han SG: Aluminum exposure promotes the metastatic proclivity of human colorectal cancer cells through matrix metalloproteinases and the TGF-beta/Smad signaling pathway. Food Chem Toxicol 141: 111402, 2020.

141. Omran GA: Hematological and immunological impairment following in-utero and postnatal exposure to aluminum sulfate in female offspring of albino rats. Immunopharmacol Immunotoxicol 41: 40-47, 2019.

142. Moulahoum H, Boumaza BMA, Ferrat M and Djerdjouri B: Arsenic trioxide exposure accelerates colon preneoplasic aberrant crypt foci induction regionally through mitochondrial dysfunction. Toxicol Res 7: 182-190, 2018

143.Zeng HL, Yang Q, Yuan P, Wang X and Cheng L: Associations of essential and toxic metals/metalloids in whole blood with both disease severity and mortality in patients with COVID-19. FASEB J 35: e21392, 2021

144.Zhang WH, Huang J, Feng M, Tong YQ, Guan XH, Jiang HW and Wei S: Elevated Arsenic Exposure Is Associated with an Increased Risk of Chronic Hepatitis B Virus Infection: NHANES (2003-2014) in US Adults. Curr Med Sci 38: 610-617, 2018.

145.Di Ciaula A: Asbestos ingestion and gastrointestinal cancer: a possible underestimated hazard. Expert Rev Gastroenterol Hepatol 11: 419-425, 2017.

146. Musk AW, de Klerk N, Reid A, Hui J, Franklin P and Brims F: Asbestos-related diseases. Int J Tuberc Lung Dis 24: 562-567, 2020.

147. Talibov M, Sormunen J, Hansen J, Kjaerheim K, Martinsen JI, Sparen P, Tryggvadottir L, Weiderpass E and Pukkala E: Benzene exposure at workplace and risk of colorectal cancer in four Nordic countries. Cancer Epidemiol 55: 156-161, 2018.

148. Luo Y, Yan J and McClure S: Distribution of the environmental and socioeconomic risk factors on COVID-19 death rate across continental USA: A spatial nonlinear analysis. Environ Sci Pollut Res Int 28: 6587-6599, 2021.

149. Hosgood HD, III, Zhang L, Shen M, Berndt SI, Vermeulen R, Li G, Yin S, Yeager M, Yuenger J, Rothman N, et al: Association between genetic variants in VEGF, ERCC3 and occupational benzene haematotoxicity. Occup Environ Med 66: 848-853, 2009.

150. Morinaga K, Oshima A and Hara I: Multiple primary cancers following exposure to benzidine and beta naphthylamine. Am J Ind Med 3: 243-246, 1982.

151. Hu H, Zheng Y, Wen X, Smith SS, Nizomov J, Fishe J, Hogan WR, Shenkman EA and Bian J: An external exposome-wide association study of COVID-19 mortality in the United States. Sci Total Environ 768: 144832-144832, 2021.

152. Luster MI, Tucker AN, Hayes HT, Pung OJ, Burka T, McMillan R and Eling T: Immunosuppressive effects of benzidine in mice - evidence of alterations in arachidonic-acid metabolism. J Immunol 135: 2754-2761, 1985.

153. Bolli A, Bulzomi P, Galluzzo P, Acconcia F and Marino M: Bisphenol A Impairs Estradiol-induced Protective Effects Against DLD-1 Colon Cancer Cell Growth. IUBMB Life 62: 684-687, 2010.

154.Zahra A, Sisu C, Silva E, De Aguiar Greca SC, Randeva HS, Chatha K, Kyrou I and Karteris E: Is There a Link between Bisphenol A (BPA), a Key Endocrine Disruptor, and the Risk for SARS-CoV-2 Infection and Severe COVID-19? J Clin Med 9: 3296, 2020.

155. Abedelhaffez AS, El-Aziz EAA, Aziz MAA and Ahmed AM: Lung injury induced by Bisphenol A: A food contaminant, is ameliorated by selenium supplementation. Pathophysiology 24: 81-89, 2017. 
156. Naji S, Issa K, Eid A, Iratni R and Eid AH: Cadmium Induces Migration of Colon Cancer Cells: Roles of Reactive Oxygen Species, P38 and Cyclooxygenase-2. Cell Physiol Biochem 52: 1517-1534, 2019.

157.Zeng HL, Zhang B, Wang X, Yang Q and Cheng L: Urinary trace elements in association with disease severity and outcome in patients with COVID-19. Environ Res 194: 110670, 2021.

158. Krueger WS and Wade TJ: Elevated blood lead and cadmium levels associated with chronic infections among non-smokers in a cross-sectional analysis of NHANES data. Environ Health 15: $16,2016$.

159. Jacobi CA, Sabat R, Bohm B, Zieren HU, Volk HD and Müller JM: Pneumoperitoneum with carbon dioxide stimulates growth of malignant colonic cells. Surgery 121: 72-78, 1997.

160. Duarte CM, Jaremko L and Jaremko M: Hypothesis: Potentially Systemic Impacts of Elevated $\mathrm{CO}_{2}$ on the Human Proteome and Health. Front Public Health 8: 543322, 2020.

161. Kato K, Kawai T, Fujii M, Bunai Y, Shima H and Takahashi M: Enhancing effect of preadministration of carbon tetrachloride on methylazoxymethanol acetate-induced intestinal carcinogenesis. J Toxicol Sci 10: 289-294, 1985.

162. Unsal V, Cicek M and Sabancilar İ: Toxicity of carbon tetrachloride, free radicals and role of antioxidants. Rev Environ Health: Sep 24, 2020 (Epub ahead of print) doi: 10.1515/reveh-2020-0048.

163. Mills PK and Yang RC: Agricultural exposures and gastric cancer risk in Hispanic farm workers in California. Environ Res 104: 282-289, 2007.

164. Tryphonas H, Bondy G, Hodgen M, Coady L, Parenteau M, Armstrong C, Hayward S and Liston V: Effects of cis-nonachlor, trans-nonachlor and chlordane on the immune system of Sprague-Dawley rats following a 28-day oral (gavage) treatment. Food Chemi Toxicol 41: 107-118, 2003.

165.El-Tawil AM: Colorectal cancers and chlorinated water. World J Gastrointest Oncol 8: 402-409, 2016.

166. Bornstein SR, Voit-Bak K, Schmidt D, Morawietz H, Bornstein AB, Balanzew W, Julius U, Rodionov RN, Biener AM, Wang J, et al: Is There a Role for Environmental and Metabolic Factors Predisposing to Severe COVID-19? Horm Metab Res 52: 540-546, 2020

167. Gao S, Wang Y,Zhang P, Dong Y and Li B: Subacute oral exposure to dibromoacetic acid induced immunotoxicity and apoptosis in the spleen and thymus of the mice. Toxicol Sci 105: 331-341,2008.

168. McDorman KS, Chandra S, Hooth MJ, Hester SD Schoonhoven R and Wolf DC: Induction of transitional cell hyperplasia in the urinary bladder and aberrant crypt foci in the colon of rats treated with individual and a mixture of drinking water disinfection by-products. Toxicol Pathol 31: 235-242, 2003

169. Keegan TE, Simmons JE and Pegram RA: NOAEL and LOAEL determinations of acute hepatotoxicity for chloroform and bromodichloromethane delivered in an aqueous vehicle to F344 rats. J Toxicol Environ Health-Part A 55: 65-75, 1998.

170. Suriyo T, Tachachartvanich $P$, Visitnonthachai $D$, Watcharasit $P$ and Satayavivad J: Chlorpyrifos promotes colorectal adenocarcinoma H508 cell growth through the activation of EGFR/ERK1/2 signaling pathway but not cholinergic pathway. Toxicology 338: 117-129, 2015.

171. Chen YC, Pai MH, Chen YT and Hou YC: Dietary exposure to chlorpyrifos affects systemic and hepatic immune-cell phenotypes in diabetic mice. Toxicology 452: 152698, 2021.

172. Chappell GA, Wikoff DS and Thompson CM: Assessment of Mechanistic Data for Hexavalent Chromium-Induced Rodent Intestinal Cancer Using the Key Characteristics of Carcinogens. Toxicol Sci 180: 38-50, 2021.

173. Antonini JM and Roberts JR: Chromium in stainless steel welding fume suppresses lung defense responses against bacterial infection in rats. J Immunotoxicol 4: 117-127, 2007.

174. Kirkeleit J, Riise T, Bjorge T, Moen BE, Bratveit M and Christiani DC: Increased risk of oesophageal adenocarcinoma among upstream petroleum workers. Occup Environ Med 67: 335-340, 2010.

175. McLoone P, Dyussupov O, Nurtlessov Z, Kenessariyev U and Kenessary D: The effect of expsoure to crude oil on the immune system. Health implications for people living near oil exploration activities. Int J Environ Health Res 31: 762-787, 2021.

176. Chen HP, Pan MH, Chou YY, Sung C, Lee KH, Leung CM and Hsu PC: Effects of di(2-ethylhexyl)phthalate exposure on 1,2-dimethyhydrazine-induced colon tumor promotion in rats. Food Chem Toxicol 103: 157-167, 2017.
177. Adamovsky O, Buerger AN, Vespalcova H, Sohag SR, Hanlon AT, Ginn PE, Craft SL, Smatana S, Budinska E, Persico M, et al: Evaluation of Microbiome-Host Relationships in the Zebrafish Gastrointestinal System Reveals Adaptive Immunity Is a Target of Bis(2-ethylhexyl) Phthalate (DEHP) Exposure. Environ Sci Technol 54: 5719-5728, 2020.

178. Martínez Góngora V, Matthes KL, Castaño PR, Linseisen J and Rohrmann S: Dietary Heterocyclic Amine Intake and Colorectal Adenoma Risk: A Systematic Review and Meta-analysis. Cancer Epidemiol Biomarkers Prev 28: 99-109, 2019.

179. Yun $\mathrm{CH}$, Son $\mathrm{CG}$, Jung $\mathrm{U}$ and Han SH: Immunosuppressive effect of 2-amino-1-methyl-6-phenylimidazo 4,5-b pyridine (PhIP) through the inhibition of T-lymphocyte proliferation and IL-2 production. Toxicology 217: 31-38, 2006

180. Suman S, Kumar S, Moon BH, Fornace AJ Jr and Datta K: Low and high dose rate heavy ion radiation-induced intestinal and colonic tumorigenesis in $\mathrm{APC}^{1638 \mathrm{~N} /+}$ mice. Life Sci Space Res (Amst) 13: 45-50, 2017.

181. Baselet B, Sonveaux P, Baatout S and Aerts A: Pathological effects of ionizing radiation: endothelial activation and dysfunction. Cell Mol Life Sci 76: 699-728, 2019.

182. Kim H, Lee J, Woo HD, Kim DW, Oh JH, Chang HJ, Sohn DK, Shin A and Kim J: Dietary mercury intake and colorectal cancer risk: A case-control study. Clin Nutr 39: 2106-2113, 2020.

183. Silbergeld EK, Sacci JB and Azad AF: Mercury exposure and murine response to Plasmodium yoelii infection and immunization. Immunopharmacol Immunotoxicol 22: 685-695, 2000.

184. Yan X, Zhang Y, Lu Y, He L, Qu J, Zhou C, Hong P, Sun S, Zhao H, Liang Y, et al: The Complex Toxicity of Tetracycline with Polystyrene Spheres on Gastric Cancer Cells. Int J Environ Res Public Health 17: 2808, 2020.

185. Hirt $\mathrm{N}$ and Body-Malapel M: Immunotoxicity and intestinal effects of nano- and microplastics: A review of the literature. Part Fibre Toxicol 17: 57, 2020.

186.Zijno A, De Angelis I, De Berardis B, Andreoli C, Russo MT, Pietraforte D, Scorza G, Degan P, Ponti J, Rossi F and Barone F: Different mechanisms are involved in oxidative DNA damage and genotoxicity induction by $\mathrm{ZnO}$ and $\mathrm{TiO}_{2}$ nanoparticles in human colon carcinoma cells. Toxicol In Vitro 29: 1503-1512, 2015.

187. Calderón-Garcidueñas L, Torres-Jardón R, Franco-Lira M, Kulesza R, González-Maciel A, Reynoso-Robles R, Brito-Aguilar R, García-Arreola B, Revueltas-Ficachi P, Barrera-Velázquez JA, et al: Environmental Nanoparticles, SARS-CoV-2 Brain Involvement, and Potential Acceleration of Alzheimer's and Parkinson's Diseases in Young Urbanites Exposed to Air Pollution. J Alzheimers Dis 78: 479-503, 2020.

188. Chakraborty S, Castranova V, Perez MK and Piedimonte G: Nanoparticles increase human bronchial epithelial cell susceptibility to respiratory syncytial virus infection via nerve growth factor-induced autophagy. Physiol Rep 5: e13344, 2017.

189. Lightfoot NE, Berriault CJ, Seilkop SK and Conard BR: Nonrespiratory mortality and cancer incidence in a cohort of Canadian nickel workers. Arch Environ Occup Health 72: 187-203, 2017

190. Guo H, Liu H, Jian Z, Cui H, Fang J, Zuo Z, Deng J, Li Y, Wang X, Zhao L, et al: Immunotoxicity of nickel: Pathological and toxicological effects. Ecotoxicol Environ Saf 203: 111006, 2020.

191. Schullehner J, Hansen B, Thygesen M, Pedersen CB and Sigsgaard T: Nitrate in drinking water and colorectal cancer risk: A nationwide population-based cohort study. Int J Cancer 143: 73-79, 2018

192. Alamdari DH, Moghaddam AB, Amini S, Keramati MR, Zarmehri AM, Alamdari AH, Damsaz M, Banpour H, Yarahmadi A and Koliakos G: Application of methylene blue -vitamin C -N-acetyl cysteine for treatment of critically ill COVID-19 patients, report of a phase-I clinical trial. Eur J Pharmacol 885: 173494, 2020.

193. Rodríguez-Estival J, Martínez-Haro M, Martín-Hernando MA and Mateo R: Sub-chronic effects of nitrate in drinking water on red-legged partridge (Alectoris rufa): Oxidative stress and T-cell mediated immune function. Environ Res 110: 469-475, 2010.

194. Jakszyn P and Gonzalez CA: Nitrosamine and related food intake and gastric and oesophageal cancer risk: A systematic review of the epidemiological evidence. World J Gastroenterol 12: 4296-4303, 2006

195. Gao XQ, Fei F, Huo HH, Huang B, Meng XS, Zhang T and Liu BL: Impact of nitrite exposure on plasma biochemical parameters and immune-related responses in Takifugu rubripes. Aquat Toxicol 218: 105362, 2020. 
196. Ethan CJ, Mokoena KK, Yu Y, Shale K, Fan Y, Rong J and Liu F: Association between $\mathrm{PM}_{2.5}$ and mortality of stomach and colorectal cancer in Xi'an: A time-series study. Environ Sci Pollut Res Int 27: 22353-22363, 2020.

197. Ogen Y: Assessing nitrogen dioxide $\left(\mathrm{NO}_{2}\right)$ levels as a contributing factor to coronavirus (COVID-19) fatality. Sci Total Environ 726: 138605, 2020

198. Pathmanathan S, Krishna MT, Blomberg A, Helleday R, Kelly FJ, Sandström T, Holgate ST, Wilson SJ and Frew AJ Repeated daily exposure to $2 \mathrm{ppm}$ nitrogen dioxide upregulates the expression of IL-5, IL-10, IL-13, and ICAM-1 in the bronchial epithelium of healthy human airways. Occup Environ Med 60 892-896, 2003.

199. Howsam M, Grimalt JO, Guinó E, Navarro M, Martí-Ragué J, Peinado MA, Capellá G, Moreno V; Bellvitge Colorectal Cancer Group: Organochlorine exposure and colorectal cancer risk. Environ Health Perspect 112: 1460-1466, 2004

200.Lie E, Larsen HJ, Larsen S, Johansen GM, Derocher AE, Lunn NJ, Norstrom RJ, Wiig $\varnothing$ and Skaare JU: Does high organochlorine (OC) exposure impair the resistance to infection in polar bears (Ursus maritimus)? Part 1: Effect of OCs on the humoral immunity. J Toxicol Environ Health A 67: 555-582, 2004

201.Li Y, Fu Y, Hu K, Zhang Y, Chen J, Zhang S, Zhang B and Liu Y: Positive correlation between human exposure to organophosphate esters and gastrointestinal cancer in patients from Wuhan, China. Ecotoxicol Environ Saf 196: 110548, 2020.

202. Rajak P, Ganguly A, Sarkar S, Mandi M, Dutta M, Podder S, Khatun S and Roy S: Immunotoxic role of organophosphates: An unseen risk escalating SARS-CoV-2 pathogenicity. Food Chem Toxicol 149: 112007, 2021.

203. Medina-Buelvas DM, Estrada-Muñiz E, Rodríguez-Sosa M, Shibayama $M$ and Vega L: Increased heart fibrosis and acute infection in a murine Chagas disease model associated with organophosphorus pesticide metabolite exposure. Sci Rep 9: $17539,2019$.

204. Cheng J, Su H and Xu Z: Intraday effects of outdoor air pollution on acute upper and lower respiratory infections in Australian children. Environ Pollut 268: 115698, 2021.

205.Lin YC, Wei PL, Tsai YT, Wong JH, Chang CM, Wang JY, Hou MF, Lee YC, Chuang $\mathrm{HY}$ and Chang WC: $\mathrm{Pb}^{2+}$ induced IL-8 gene expression by extracellular signal-regulated kinases and the transcription factor, activator protein 1, in human gastric carcinoma cells. Environ Toxicol 30: 315-322, 2015.

206.Fernandez-Cabezudo MJ, Ali SA, Ullah A, Hasan MY, Kosanovic M, Fahim MA, Adem A and al-Ramadi BK: Pronounced susceptibility to infection by Salmonella enterica serovar Typhimurium in mice chronically exposed to lead correlates with a shift to Th2-type immune responses. Toxicol Appl Pharmacol 218: 215-226, 2007.

207. Miao C, Ma J, Zhang Y, Chu Y, Li J, Kuai R, Wang S and Peng H: Perfluorooctanoic acid enhances colorectal cancer DLD-1 cells invasiveness through activating NF- $\kappa B$ mediated matrix metalloproteinase-2/-9 expression. Int $\mathrm{J}$ Clin Exp Pathol 8 10512-10522, 2015

208. Ait Bamai Y, Goudarzi H, Araki A, Okada E, Kashino I, Miyashita $\mathrm{C}$ and Kishi R: Effect of prenatal exposure to per- and polyfluoroalkyl substances on childhood allergies and common infectious diseases in children up to age 7 years: The Hokkaido study on environment and children's health. Environ Int 143 105979,2020

209. Huang X, Guan S, Wang J, Zhao L, Jia Y, Lu Z, Yin C, Yang S Song Q, Han L, et al: The effects of air pollution on mortality and clinicopathological features of esophageal cancer. Oncotarget 8 : 58563-58576, 2017.

210. Hutter HP, Poteser M, Moshammer H, Lemmerer K, Mayer M, Weitensfelder L, Wallner P and Kundi M: Air Pollution Is Associated with COVID-19 Incidence and Mortality in Vienna, Austria. Int J Environ Res Public Health 17: 9275, 2020.

211. Farina F, Sancini G, Battaglia C, Tinaglia V, Mantecca P, Camatini M and Palestini P: Milano Summer Particulate Matter (PM10) Triggers Lung Inflammation and Extra Pulmonary Adverse Events in Mice. PLoS One 8: e56636, 2013.

212. Meo SA, Abukhalaf AA, Alomar AA, Alessa OM, Sami W and Klonoff DC: Effect of environmental pollutants PM-2.5, carbon monoxide, and ozone on the incidence and mortality of SARS-COV-2 infection in ten wildfire affected counties in California. Sci Total Environ 757: 143948, 2021.
213.Zhu H, Wu Y, Kuang X, Liu H, Guo Z, Qian J, Wang D, Wang M, Chu H, Gong W, et al: Effect of PM2.5 exposure on circulating fibrinogen and IL-6 levels: A systematic review and meta-analysis. Chemosphere 271: 129565-129565, 2021.

214. Stølevik SB, Nygaard UC, Namork E, Haugen M, Meltzer HM, Alexander J, Knutsen HK, Aaberge I, Vainio K, van Loveren $\mathrm{H}$, et al: Prenatal exposure to polychlorinated biphenyls and dioxins from the maternal diet may be associated with immunosuppressive effects that persist into early childhood. Food Chem Toxicol 51: 165-172, 2013

215. Roshandel G, Semnani S, Malekzadeh R and Dawsey SM: Polycyclic aromatic hydrocarbons and esophageal squamous cell carcinoma. Arch Iran Med 15: 713-722, 2012

216. Domingo JL and Rovira J: Effects of air pollutants on the transmission and severity of respiratory viral infections. Environ Res 187: 109650, 2020

217.Låg M, Øvrevik J, Refsnes M and Holme JA: Potential role of polycyclic aromatic hydrocarbons in air pollution-induced non-malignant respiratory diseases. Respir Res 21: 299, 2020.

218. Lee W, Ahn YS, Lee S, Song BM, Hong S and Yoon JH Occupational exposure to crystalline silica and gastric cancer: a systematic review and meta-analysis. Occup Environ Med 73 794-801, 2016

219. Naidoo RN and Jeebhay MF: COVID-19: a new burden of respiratory disease among South African miners? Curr Opin Pulm Med 27: 79-87, 2021.

220. Benmerzoug S, Bounab B, Rose S, Gosset D, Biet F, Cochard T, Xavier A, Rouxel N, Fauconnier L, Horsnell WGC, et al: Sterile Lung Inflammation Induced by Silica Exacerbates Mycobacterium tuberculosis Infection via STING-Dependent Type 2 Immunity. Cell Rep 27: 2649-2664.e5, 2019.

221. Chang CJ, Tu YK, Chen PC and Yang HY: Talc exposure and risk of stomach cancer: Systematic review and meta-analysis of occupational cohort studies. J Formos Med Assoc 119: 781-792, 2020.

222. Radić I, Vucak I, Milosević J, Marusić A, Vukicević S and Marusić M: Immunosuppression induced by talc granulomatosis in the rat. Clin Exp Immunol 73: 316-321, 1988.

223. Xie G, Peng Z and Raufman JP: Src-mediated aryl hydrocarbon and epidermal growth factor receptor cross talk stimulates colon cancer cell proliferation. Am J Physiol Gastrointest Liver Physiol 302: G1006-G1015, 2012

224. Fiorito F, Santamaria R, Irace C, De Martino L and Iovane G: 2,3,7,8-tetrachlorodibenzo-p-dioxin and the viral infection. Environ Res 153: 27-34, 2017.

225. Fredriksson M, Bengtsson NO, Hardell L and Axelson O: Colon cancer, physical activity, and occupational exposures. A case-control study. Cancer 63: 1838-1842, 1989

226. Selgrade MK and Gilmour MI: Suppression of pulmonary host defenses and enhanced susceptibility to respiratory bacterial infection in mice following inhalation exposure to trichloroethylene and chloroform. J Immunotoxicol 7: 350-356, 2010

227. Hou N, Zhang X, Zhao L, Zhao X, Li Z, Song T and Huang C: A novel chronic stress-induced shift in the Th1 to Th2 response promotes colon cancer growth. Biochem Biophys Res Commun 439: 471-476, 2013.

228. Lamontagne SJ, Pizzagalli DA and Olmstead MC: Does inflammation link stress to poor COVID-19 outcome? Stress Health 37: 401-414, 2021.

229. Schmidt SAJ, Sørensen HT, Langan SM and Vestergaard M: Perceived psychological stress and risk of herpes zoster: A nationwide population-based cohort study. Br J Dermatol 185 : $130-138,2021$

230. Lin Q, Wang F, Yang R, Zheng X, Gao H and Zhang P: Effect of Chronic Restraint Stress on Human Colorectal Carcinoma Growth in Mice. Plos One 8: e61435, 2013.

231. Cai Y, Li YF, Tang LP, Tsoi B, Chen M, Chen H, Chen XM, Tan RR, Kurihara H and He RR: A new mechanism of vitamin C effects on $\mathrm{A} / \mathrm{FM} / 1 / 47(\mathrm{H} 1 \mathrm{~N} 1)$ virus-induced pneumonia in restraint-stressed mice. Biomed Res Int 2015: 675149, 2015.

This work is licensed under a Creative Commons Attribution-NonCommercial-NoDerivatives 4.0 International (CC BY-NC-ND 4.0) License. 